\title{
La emergencia de nuevos modelos productivos: La participación de los trabajadores y la fabricación del consentimiento en la producción ${ }^{1}$
}

\author{
ARTURO LAHERA SÁNCHEZ \\ Departamento de Sociología III \\ Facultad de CC. Políticas y Sociología \\ Universidad Complutense. Madrid
}

1. LA EMERGENCIA DE NUEVOS MODELOS PRODUCTIVOS DE ORGANIZACIÓN DEL TRABAJO HUMANO

En las últimas tres décadas uno de los ejes fundamentales del desarrollo de la sociología del trabajo, así como de otras ciencias sociales del trabajo, ha consistido en reflexionar sobre el grado de vigencia o de superación de la tradicional organización del proceso de trabajo, representada por el taylorismo, tanto por sus principios teóricos o discursivos como por las prácticas empresariales a las que dio lugar, todo ello en relación a sus efectos sobre las condiciones de trabajo y a sus ventajas o desventajas en la consecución de los objetivos productivos y de calidad de las empresas. Este debate ininterrumpido se hizo más intenso, sin duda alguna, con la entrada en crisis del largo periodo de acumulación de la segunda posguerra mundial en la década de los setenta; desde entonces se ha asistido a interminables reflexiones sobre cómo reorganizar los procesos productivos y de trabajo para hacer frente a unas nuevas condiciones económicas y comerciales, basadas en la supuesta crisis de la producción masiva y estandarizada de bienes y servicios que había caracterizado ese periodo de posguerra y que había sido articulada por los principios, valores y técnicas o dispositivos de gestión del propio taylorismo.

\footnotetext{
1 Este artículo se basa en las reflexiones teóricas y en el trabajo de campo de mi tesis doctoral: La emergencia de nuevos modelos productivos y la participación de los trabajadores: diseño e implantación de conceptos antropocéntricos de producción en empresas fabricantes de máquinas-herramienta (Lahera Sánchez 2000), realizada en el Departamento de Sociología III, Facultad de Ciencias Políticas y Sociología, de la Universidad Complutense de Madrid. Esta investigación ha sido dirigida por el profesor Juan José Castillo, al que agradezco su continua dedicación, preocupación y confianza; condiciones de trabajo que han facilitado mi formación teórica y de terreno.
} 
De hecho, hace ya más de tres décadas que se comenzaron a introducir, generalmente de forma minoritaria y limitada, técnicas organizativas como los grupos de producción, la rotación entre puestos, la ampliación $y$ enriquecimiento de tareas, etc. (Castillo 1991), para reestructurar el funcionamiento productivo de las empresas en un nuevo contexto industrial y económico. Pues bien, en los años noventa volvió a aflorar de una manera destacada una reflexión sobre la emergencia de nuevos modelos productivos en las empresas, es decir, una supuesta nueva articulación de paradigmas para reorganizar los procesos productivos en los que se ha enfatizado la necesidad de la participación destacada de los trabajadores y la necesaria ruptura con la vieja y tradicional división del trabajo (VV. AA. 1997). La emergencia de estos nuevos modelos supone, por tanto, la recuperación o mantenimiento de anteriores argumentos sobre la necesaria reorganización y humanización del proceso de trabajo, pero haciendo, eso sí, mayor hincapié en la implicación de los trabajadores en la gestión participativa de su actividad, de los resultados de la producción y su calidad: principios que han logrado una difusión teórica e ideológica de alcance mundial a través de las prácticas gerenciales basadas en los criterios de la producción ligera toyotista (Womack, Jones y Roos 1991), algunos de los cuales han sido recogidos también por la alternativa antropocéntrica europea (Wobbe 1991).

En general, los discursos teóricos sobre la emergencia de nuevos modelos productivos identifican a éstos por articular dispositivos y prácticas organizativas, basados en la participación incrementada de los trabajadores, la descentralización de decisiones y la autonomía en la gestión del trabajo en favor de los operadores directos de taller (Boyer y Freyssenet 1996; Castillo 1996). Lo fundamental es destacar que estas "nuevas" apuestas organizativas suponen realmente "nuevos conceptos productivos" (Kern y Schumann 1988) e interpretaciones sobre las capacidades de los trabajadores y sus conocimientos, sobre su utilidad ineludible en los procesos de trabajo. Estos nuevos conceptos suponen abogar por el aprovechamiento al máximo de la capacidad individual del trabajador, su colaboración para mejorar su eficacia, aprovechar su saber y su creatividad colectiva para un aumento de la productividad y de la flexibilidad, creando una nueva cooperación entre capital y trabajo, en la que la mejora de las condiciones de trabajo debe centrarse en desarrollar los recursos humanos, todo ello a través de la integración de tareas y funciones productivas, mediante el desenvolvimiento de la profesionalidad (conocimientos, cualificaciones y pericias) de la mano de obra, su autonomía y su polivalencia (Butera 1986: 43). "Si para el taylorismo el trabajo humano era un obstáculo en la producción, en estos nuevos conceptos es un recurso" (Wood 1989: 12). 
El eje central sobre el que se articularán la emergencia de estos nuevos modelos productivos (en lo referente a la organización del trabajo) $\mathrm{y}$, sobre todo, las prácticas a las que puedan dar lugar, está en reconocer empresarialmente que la actividad, el conocimiento y la experiencia laboral del colectivo de trabajadores es un recurso productivo clave a movilizar para adaptarse a las nuevas contingencias de los mercados; es decir, que es necesario aprovechar de forma más amplia las competencias del factor humano. Mientras que la racionalización promovida e implantada por la organización taylorista supone que el trabajo humano es una barrera en la producción que es necesario vencer con técnicas y dispositivos de organización restrictiva, esta nueva apuesta organizativa defiende conceptos productivos que suponen un cambio paradigmático en el ideario y los marcos de significado sobre la organización del trabajo humano y. su papel en el proceso productivo (Wood 1989: 12). Estos nuevos conceptos promueven una racionalización en que se busca aprovechar las cualificaciones, experiencias y recursos culturales del trabajador, al que se reconoce un mayor espacio de acción en el que pueda desarrollar y aplicar su inteligencia de producción, es decir, sus conocimientos, capacidades y su creatividad, para así mejorar tanto su productividad como la calidad de la producción, que se ha convertido en un elemento destacado en la nueva competencia mundializada en los mercados (Kern y Schumann 1988: 7-20). La movilización de esa, ahora reconocida, inteligencia de producción en manos de los trabajadores supone que la eficiencia empresarial debe lograrse respetando, potenciando y facilitando su propia capacidad de gestión, y no estableciendo prácticas que limiten y coarten esa autogestión, lo que implica, frente al taylorismo, recuperar la autonomía en el trabajo, eliminada, controlada y vigilada por la organización tradicional del trabajo ${ }^{2}$. Como se señalaba anteriormente, esta concepción alternativa que considera al trabajador como un gestor inteligente de la producción implica incrementar su actividad a partir de la creatividad y la subjetividad del propio trabajador ${ }^{3}$, o, lo que es lo mismo, se construye un nuevo paradigma para lograr incrementar el rendimiento de la fuerza de trabajo, que sigue siendo el objetivo fundamental de la práctica empresarial (Schumann 1999). Aparece dentro de esta concepción la necesidad gerencial de que los trabajadores se involucren en la mejora

2 Supone devolver al trabajo humano la "soberanía productiva" sobre el proceso de trabajo, al obrero colectivo (Kern y Schumann 1988).

3 "Lo participativo sería la vía elegida para limitar los efectos devastadores de una delimitación de tareas que impide toda difusión de los saberes y los conocimientos tácitos de los ejecutantes* (Linhart 1990: 36). 
continua del proceso de trabajo, es decir, que apliquen -como se analizará más adelante- con autonomía su inteligencia de producción para crear, ininterrumpidamente desde el taller, procedimientos o métodos que reduzcan los tiempos de fabricación e incrementen la calidad de sus resultados; que apliquen su conocimiento experto para mejorar los resultados económicos de las empresas.

En general, los nuevos conceptos productivos se basan en principios que critican o se contraponen a los articulados por la racionalización taylorista. Frente a la extrema división y parcelación de tareas de la Organización Científica del Trabajo, estos nuevos conceptos se centran en la integración de tareas a desempeñar por cada trabajador, al tiempo que se descentraliza la organización para superar la fractura entre concepción y ejecución, abogando por reestablecer la autonomía de los trabajadores en la gestión de su actividad y convirtiendo al trabajador en parte activa de ese proceso de racionalización, al desempeñar funciones de mayor responsabilidad (calidad, mantenimiento, planificación), lo que implicará necesariamente un trabajo más interesante y cualificador (Sandberg 1995). Sus defensores justifican la pertinencia de la adopción de prácticas basadas en estos innovadores principios organizativos -que desarrollan los recursos humanos y su reprofesionalización — por la reducción de los tiempos productivos, el incremento de utilización de los sistemas técnicos y la mejora de la calidad que conllevan, permitiendo "extraordinarias ganancias de eficiencia" (Schumann 1999: 87).

En definitiva, estos nuevos conceptos productivos dan lugar a intentos de reorganización que buscan elevar la eficiencia productiva utilizando mejor los recursos humanos, la fuerza de trabajo, lo que requiere con el fin de rentabilizar productivamente su inteligencia de producciónque los trabajadores estén dispuestos a movilizar en favor de la empresa sus conocimientos, experiencia y creatividad. Su implantación se basa gerencialmente en reconocer la necesidad de abrir los espacios de actuación autónoma a los propios trabajadores; es decir, incrementar la autonomía en el trabajo y la discrecionalidad de los operadores en la gestión de su propia actividad. La gestión participativa de los recursos bumanos aparece así como el dispositivo o herramienta directiva que permitirá precisamente vincular a los trabajadores a los objetivos empresariales y explotar sus reservas de conocimientos, de manera que dejen de ser "clandestinos" y puedan emplearse para mejorar el proceso de producción desde el propio trabajo directo de taller. 


\section{LA PARTICIPACIÓN DE LOS TRABAJADORES COMO NUEVO CONCEPTO PRODUCTIVO: LA GESTIÓN PARTICIPATIVA DE LOS RECURSOS HUMANOS}

El paradigma organizativo tradicional representado por el taylorismo supone en términos de relaciones industriales establecer una interpretación del rol productivo del trabajo humano, basado en reducir al máximo la autonomía y la discrecionalidad de los operadores: éstos tan sólo deben realizar sus tareas siguiendo rígidamente los procedimientos operativos diseñados e impuestos por los organizadores de la producción, que centralizan el poder de configurar los caracteres del proceso de trabajo y se reservan su concepción, mientras al trabajo humano directo se le reducen sus ámbitos de actuación y decisión a los límites designados en los procedimientos estandarizados y cronometrados del análisis de tiempos y movimientos (Taylor 1925 y 1971; US Commission on Industrial Relations 1914; Friedmann 1978). El taylorismo como paradigma hegemónico industrial de organización del trabajo se basa en la no-participación de los operadores en la definición, tanto de los métodos de producción como en la regulación del flujo de producción. Esta no-participación implica construir el vínculo relacional entre capital y trabajo a través de la posición y la práctica autoritaria de los organizadores de la producción, de la oficina técnica y de métodos, que detenta monopolísticamente la capacidad de tomar decisiones sobre cómo organizar, configurar, articular y dar contenido a las cualificaciones y tareas de los operadores, que quedan al margen de cualquier posibilidad de intervención en el diseño del proceso, denegándoseles la capacidad de decidir y quedando subsumidos a la lógica heterónoma impuesta por los organizadores de la producción ("al poder de los ingenieros").

Sin embargo, para el taylorismo la construcción de las relaciones industriales a partir de la subordinación total del trabajo a las prácticas del capital, basadas en la transferencia de la inteligencia de producción desde el taller a la oficina, era la condición para lograr evitar el conflicto inmanente de esa relación, es decir, el dispositivo mediante el que lograr un orden en la producción que superara las posibilidades de confrontación abierta con los trabajadores del taller y para evitar que las acciones individuales o colectivas de éstos interrumpieran la fluidez del proceso productivo. Precisamente, la ideología taylorista, mediante su concepción economicista sobre la condición humana del trabajador, supone que el establecimiento del trabajo a destajo, a prima o a pieza es el dispositivo o la tecnología social ${ }^{4}$

4 Por "tecnología social o política" se entiende todo dispositivo construido para acuñar, modelar o forzar un comportamiento o una práctica en los sujetos, en este caso los trabajadores. 
que permite, no sólo crear ese orden, sino asegurar el proceso de producción y la intensificación del trabajo efectivo que se puede obtener de una fuerza de trabajo en un mismo periodo de tiempo: el destajo incrementa tanto la producción como el salario de los trabajadores (también abarata las mercancías que los trabajadores necesitan para su reproducción), lo que para el taylorismo suponía articular armoniosamente los intereses originariamente conflictivos de capital y trabajo.

Mediante la manipulación de un artefacto salarial se logra el orden en la producción, al tiempo que para que los trabajadores puedan lograr la optimización de sus salarios a cambio de la venta de su fuerza de trabajo deben seguir escrupulosamente las consignas, métodos, procedimientos e indicaciones de los organizadores de la producción: sólo su aceptación incondicional e incuestionada les permitirá cumplir el objetivo de aumentar sus ingresos. Las relaciones industriales son así expresión de una relación de poder autoritario (y paternalista) entre el capital y el trabajo, ya que el papel productivo de la oficina técnica y de la ingeniería de producción es concentrar la inteligencia de producción, su aplicación y la soberanía sobre el ritmo y los contenidos de los procesos de trabajo, mientras el rol del trabajo humano directo es ejecutar invariablemente lo establecido por el capital, sin autonomía y sin poder de decisión.

Lo que interesa destacar es que la no-participación del factor humano es uno de los elementos consustanciales a la Organización Científica del Trabajo taylorista, en la que la regulación de las relaciones industriales conflictivas de la economía del mercado capitalista se basa en la negación del reconocimiento de los potenciales conocimientos experienciales y empíricos de la fuerza de trabajo que, puesto que no es más que un elemento disturbador de los procesos, debe ser confinada y limitada al máximo en sus comportamientos: se rechaza su centralidad en cuanto a yacimiento de inteligencia de producción, con lo que no tiene sentido que participe, tan sólo que obedezca y que sea controlada para limitar los posibles impactos negativos que su actividad pueda tener en la consecución del objetivo empresarial de supervivencia en el mercado y de aumento de su posición competitiva en él.

Frente a este paradigma taylorista, la emergencia del debate sobre las nuevas formas de organización del trabajo y, posteriormente, sobre los nuevos conceptos productivos y su aplicación en referentes como el de la producción ligera o el de los conceptos antropocéntricos, pone también en cuestión las formas en que la organización tradicional del trabajo había construido las relaciones industriales entre capital y trabajo: la única y mejor manera de lograr rentabilizar los conocimientos y experiencias de este factor humano que aparece ahora como central en la producción es 
permitir y facilitar su participación en el proceso de definición de la organización del trabajo, es decir, que colabore de forma autónoma con los objetivos empresariales de la compañía en que desempeña su actividad $^{5}$. El reconocimiento gerencial de esta participación obrera supone reconstruir las relaciones industriales a partir de una redistribución del poder, antes centralizado en los organizadores de la producción a los trabajadores, que ahora podrán tomar parte en algunas de las atribuciones organizativas que el taylorismo otorgaba en exclusiva a la dirección.

Por tanto, dentro de los nuevos conceptos productivos, como son la ampliación y el enriquecimiento de tareas, la rotación recualificadora entre puestos y los grupos de trabajo, que pretenden movilizar y rentabilizar eficazmente los métodos empíricos que conforman la inteligencia de producción del trabajo humano, la participación de los trabajadores aparece como un dispositivo que se encuentra en la base de articulación no sólo de esas nuevas formas de organización de la producción, sino que abre las posibilidades de crear un vínculo social entre capital y trabajo, a partir de unas relaciones industriales diferenciadas respecto a los paradigmas organizativos tradicionales: "para aprovechar al máximo sus habilidades [de los trabajadores] no siempre es adecuado el diseño tradicional orientado a la especialización, la formalización y la centralización; por ello se debe buscar que las estructuras apoyen la colaboración de forma que se hagan explícitos los conocimientos e inteligencia de los empleados, lo que se favorece con la introducción de nuevos modelos de gestión que faciliten la comunicación y el trabajo en equipo con el fin de beneficiar la toma conjunta de decisiones, la resolución de problemas o la gestión del cambio" (Aragón 1998: 28), todo lo cual permitirá no sólo el incremento de los resultados empresariales, sino también la satisfacción de los operadores con su trabajo, lo que se consigue si "ayudan" a resolver los problemas productivos: "prefieren usar también sus cerebros, no sólo sus manos" (Tausky y Chelte 1988: 366). De esta forma, los efectos positivos de la participación pueden suponer el incremento de la calidad de las decisiones, al tener en cuenta las ideas y perspectivas del taller, facilitando su adopción, así como promocionar relaciones industriales más positivas y cooperativas (Cressey y Di Martino 1991: 180).

La lógica que sigue este paradigma se puede resumir en que pretende asegurar que la práctica de nuevas formas de gestión de los recursos

5 Frente al taylorismo, que obstaculiza la producción al ignorar el saber-hacer de los trabajadores, ahora se legitima éste como recurso productivo: "Los trabajadores crean conocimiento experto (craft knowledge), aprenden con el tiempo, pueden ser un recurso valioso para incrementar los resultados" (Tausky y Chelte 1988: 367). 
humanos permite vincular al trabajador con su empresa, aumentando la productividad y reduciendo los conflictos industriales; es decir, permite superar el antagonismo originario entre los actores empresariales, aprovechando no sólo las pericias y capacidades de los actores que integran la empresa, sino también su inteligencia productiva, respondiendo a una doble finalidad: mejorar tanto los resultados económicos de la empresa como la satisfacción de los operadores con sus condiciones de trabajo ${ }^{6}$ : la participación supone un nuevo dispositivo de conversión de la fuerza de trabajo en trabajo efectivo que mediante la ampliación de los límites de autonomía de los operadores permite construir un nuevo orden productivo.

Por tanto, las razones por las que los directores o los organizadores de la producción apuestan por la participación se centran en considerarla un dispositivo o tecnología social (acuñadora de comportamientos y prácticas) que puede contribuir a incrementar la eficiencia de la organización (reducción de costes, aumento de la productividad y la calidad), pudiendo reforzar el compromiso de los trabajadores con los objetivos empresariales a través de la formación de una especie de "cultura de empresa" que transforme la relación conflictiva entre capital y trabajo en una articulación armónica que mantenga la fluidez de la producción (Cressey y Di Martino 1991); es decir, está referida a la preocupación esencial de la dirección/capital: el orden, la disciplina, la desaparición de los conflictos en el taller (Gaudemar 1991: 92). Supone buscar un recambio a los dispositivos tayloristas que no lograron articular armoniosamente los intereses de los agentes empresariales y sus relaciones industriales, todo ello mediante la mutación o modelado del trabajo humano, de sus características y atribuciones productivas, orientadas ahora a que se implique armoniosamenten con los objetivos empresariales, lo cual aparece como el factor fundamental de gestión de la empresa, como el eje sobre el que desarrollar las nuevas estrategias productivas.

Precisamente, durante la segunda mitad de los años noventa, las empresas más avanzadas del sector de fabricantes de máquinas-herramienta, cuya producción se concentra fundamentalmente en la economía de Euskadi ( $75 \%$ de los productores), comenzaron a implantar nuevas políticas

\footnotetext{
6 aSe concretan en incrementos del grado de implicación personal, mejora de la autorrealización, aumento de la satisfacción laboral, afectando positivamente al desarrollo de la carrera profesional, mejora de la solución de problemas y de las actitudes de los empleados, aparición de un mejor clima laboral, y de una mayor efectividad a nivel grupal y organizacional [...]; se constatan aumentos en la productividad, incrementos en la eficacia del trabajo en grupo y disminución del absentismo y la rotación, lo que va a implicar un mayor crecimiento y unos mejores resultados de la empresa" (Aragón 1998: 101-102).
} 
y prácticas de organización del trabajo de mecanizado y montaje de los componentes de esta maquinaria, fundamental para el desarrollo productivo y tecnológico de multitud de sectores usuarios, para hacer frente a las nuevas características de un mercado interior e internacional, cada vez más segmentado, en el que la estrategia de estas empresas pasa de la fabricación de máquinas-herramienta seriadas y homogéneas a producir máquinas con mayores niveles de adaptación "a medida" para satisfacer flexiblemente las especificaciones de sus demandantes, junto con un incrementado contenido tecnológico (controles numéricos avanzados, programaciones interactivas, ingeniería asistida por ordenador...). Estas políticas han supuesto la implantación de nuevos conceptos productivos, tales como el establecimiento de células de mecanizado, grupos de montaje, ampliación y enriquecimiento de tareas, formación de operadores de mecanizado y montaje polivalentes (rotación de tareas), etc., con resultados diversos y contrapuestos en el interior de cada empresa, en sus diferentes talleres y fases del proceso de trabajo, y entre las diferentes empresas en relación a la mejora de las condiciones de trabajo de los operadores y respecto a su recualificación efectiva (Lahera Sánchez 2000). Sin embargo, la totalidad de los organizadores de la producción, direcciones e ingenierías de las cuatro empresas fabricantes de máquinas-herramienta, analizadas en el trabajo de campo de la investigación en que se basa la reflexión propuesta ${ }^{7}$, fundamentan estas políticas en la necesidad de aprovechar al máximo la inteligencia de producción de sus operadores de taller a través del incremento de su participación y autonomía en la gestión del proceso de trabajo. Aparece así la participación como la dimensión destacada para la articulación de un posible nuevo modelo productivo de organización del trabajo y de (re)construcción del orden en la producción, de relación entre capital y trabajo para reducir su conflicto. Serán los resultados obtenidos en el trabajo en los talleres de estas empresas, Buruzagi (fabricante de tornos y rectificadoras CNC), Berritzaile (fresadoras $\mathrm{CNC}$ ), Zuzendu (tornos CNC) y Eskulan (fresadoras convencionales y centros de mecanizado $\mathrm{CNC}$ ), las tres primeras en Elgóibar (Guipúzcoa) y la

7 El trabajo de campo se realizó entre marzo de 1998 y junio de 1999; las estrategias metodológicas empleadas fueron el análisis del trabajo de los operadores de mecanizado y montaje de las cuatro empresas estudiadas, la observación participante continuada en sus talleres y las entrevistas en profundidad a directores, ingenieros, comités sindicales de empresa y operadores de taller, habiéndose realizado 80 entrevistas, complementadas con visitas a centros formativos y tecnológicos del sector. Los nombres de las empresas son seudónimos para garantizar la confidencialidad a todas las personas y organismos que han colaborado desinteresadamente en esta investigación. 
última en Vitoria-Gasteiz (Álava), los que se emplearán a continuación para interpretar críticamente los objetivos organizativos y productivos de esta gestión participativa de los recursos bumanos y su efectividad en términos de reducción o eliminación del conflicto capital/trabajo, enfatizando el análisis de las perspectivas y regulaciones que la fuerza de trabajo, los operadores de mecanizado y montaje, ha desarrollado para enfrentar $O$ aceptar estos nuevos conceptos productivos participativos.

\section{LA EMPRESA COMO LABORATORIO CULTURAL DE PRODUCCIÓN DE SUJETOS}

El debate sobre la emergencia de nuevos modelos productivos, basados en la recualificación del trabajo humano y en el incremento de su participación en la gestión de los procesos de fabricación, se ha centrado empresarial y académicamente de forma dominante en presentar y discutir los resultados económicos y de calidad que se pueden obtener mediante la implantación de estos dispositivos en los centros de trabajo: los nuevos conceptos productivos de organización del trabajo se referirían así esencialmente a la fabricación de bienes y servicios. Sin embargo, es imprescindible destacar que la aplicación de la gestión participativa de los recursos humanos en la que se basan estas políticas supone también y fundamentalmente la fabricación cultural de un nuevo modelo de trabajador, que debe ahora adquirir desde el punto de vista de las gerencias de las empresas nuevas pautas de comportamiento en el trabajo que garanticen la mejora de la producción y la calidad de lo producido.

Los nuevos conceptos productivos pretenden establecer una concepción también novedosa de "ciudadanía empresarial" de los trabajadores (Miller y O'Leary 1994: 468-470), una transformación fundamental de los regímenes de fabricación y de los modos de gobernar a la fuerza de trabajo: "un cambio en el tipo de persona que debe trabajar en la fábrica" (Miller y O'Leary 1994: 477), una nueva forma de relación del trabajador con su actividad en la fábrica, caracterizada porque debe implicarse en su trabajo, vincularse a los objetivos productivos de su empresa, integrarse de manera no conflictiva con las demandas de las gerencias, para lograr así la supervivencia empresarial en un mercado mundializado cada vez más competitivo y turbulento. Se trata, por tanto, de modelar el trabajo humano, de fabricar trabajadores que participen positivamente en la gestión de su propio puesto de trabajo, una especie de nuevos ciudadanos empresariales que pueden participar activamente en la gestión del proceso de trabajo, frente a su no-participación en la organización del trabajo taylorista. 
Se fabrica o modela el trabajo humano de manera que se transformen también sus caracteres: la fuerza de trabajo debe implicarse mediante el desarrollo de una nueva actitud hacia su trabajo, hacia el proceso productivo y hacia la empresa (respecto al capital); actitud que queda reflejada en la consecución o fabricación de un factor humano con las siguientes cualificaciones o habilidades sociales (Sarriés 1994: 115-116):

a) Involucrado con las decisiones productivas de los organizadores de la producción,

b) Participativo en la definición de mejores procedimientos y formas de 'sacar' el trabajo,

c) Colaborador al máximo con su disponibilidad de conocimientos y saberes en esos objetivos,

d) Flexible en el sentido de 'adaptarse' a las continuamente cambiantes demandas de la empresa, rotando y colaborando donde se le necesite. En definitiva,

e) Confiado e integrado en la empresa, lo que permite superar el conflicto entre capital y trabajo a través de la interiorización de una interpretación integradora sobre los 'intereses armoniosos' en el seno de su compañía ${ }^{8}$.

Este tipo de participación, sinónima de implicación en el trabajo, desplaza los criterios de cualificación de las aptitudes (conocimientos formales, técnicos y tácitos) a las propias actitudes comportamentales: "así trabajadores cualificados serán aquellos confiados, implicados o integrados en los valores empresariales o en los objetivos que orientan" (Castillo 1998: 182183), es decir, "la actitud como aptitud", mayor responsabilidad y unidad en el interior de la empresa 9: se trata de lograr su implicación positiva (a favor de los objetivos gerenciales) en la producción, lo que permitirá contar con "personal más preparado; personal más implicado con los proyectos de calidad y menos reticente a los cambios; personal más flexible; personal más afín a la empresa; personal más productivo; personal más feliz" (Badía y Bellido 1999: 85; cursivas mías) ${ }^{10}$ : en definitiva, más adepto a la empresa:

8 Se trata de «lograr un consentimiento de carácter activo, efecto de la interiorización de los objetivos del capital por vía de la implicación, más o menos consciente, de su materialización. (Castillo Mendoza, en Gaudemar 1991: 22), con lo que el operador superaría la tradicional insatisfacción o alienación respecto a su actividad de trabajo al integrarse comunitariamente en los intereses empresariales, que son ahora también los suyos, debiendo estar "satisfecho" de colaborar en un objetivo común que beneficia a todos los actores. Se intenta gerencialmente fabricar una (re)socialización ideológica integradora del conflictivo trabajo humano.

9 «En la relación salarial, el obrero no vende solamente su fuerza productiva, vende también su sumisión a unas normas de comportamiento (Gaudemar 1991: 121; cursivas mías).

10 "En este sentido, los superiores deben saber delegar y dar responsabilidad a sus subordinados a la vez que controlan los resultados y los apoyan con su formación. Es 
La actitud positiva de cara a los cambios que se están introduciendo es fundamental, tanto por parte del comité de dirección, de los encargados, como a nivel de mano de obra directa. La gente rebelde es la que siempre quiere hacer valer sus iniciativas sin esperar a que haya un consenso en su área, y ahí a veces la única solución es prescindir de una persona si no quiere integrarse en un proceso de cambio de este tipo (Director de Recursos Humanos. Empresa Buruzagi).

El tipo de operario que nos demandan las empresas es que esté cada vez más preparado, que sea más competente y que lo sea en menos tiempo. Eso sí, cuando te definen el perfil de una persona que quieren incorporar a la empresa, te lo definen muy deficientemente: "quiero uno muy bueno, que no me dé problemas $y$ que tenga dedicación casi familiar a la empresa, que tenga más de veinte años para que ya esté mínimamente formado, que eche horas y trabaje en fines de semanas, igual le preocupan menos las cualificaciones reales. Nos piden operarios con características de trabajo generales, que son básicamente de comportamiento $y$ de personalidad, después vienen las técnicas (Director de Formación. Instituto de Máquina-Herramienta).

El operario o el trabajador se involucra en su realización y, por otra parte, al operario se le está dando información continuamente sobre cómo debe realizar su trabajo y cuáles son los criterios que hay que tener en cuenta a la hora de realizar ese trabajo. Se está dando y se está viendo que solamente con el cambio de actitud del personal ya se consiguen resultados mucho mejores, ya no es "me cago en la mar, me ha venido mal está piezan, no, el tío coge y analiza qué pasa con esa pieza y plantea qué habría que hacer para que esa pieza no siga mal. Es un cambio actitudinal [sic] que se está dando y se está exigiendo, se exige a la gente que cada vez se responsabilice más, y la gente a la que se da herramientas y foros para poder realizar mejor su trabajo está respondiendo pero que muy bien (Técnico de Formación en I+D. Instituto de Máquina-Herramienta).

Es aquí donde se hace más evidente que - como señalamos antesla participación tal y como es entendida en estas empresas es el nuevo dispositivo para crear no sólo ese nuevo orden productivo disciplinario, sino también el nuevo vínculo social entre capital y trabajo. Se intenta obtener individuos y colectivos de trabajadores ganados para los intereses de la empresa, que compartan una cultura común, manteniendo sus motivaciones para inventar, innovar y progresar (Linhart 1990: 42): “el intento de instrumentalizar una concepción productiva de la fábrica implica un intento de actuar sobre las acciones de los individuos de una forma específica" (Miller y O’Leary 1994: 492). Precisamente, la participación persigue la interiorización por parte de los operadores de las necesidades

muy importante la confianza en los subordinados y el dar libertad de movimientos para que éstos se sientan motivados a hacer las cosas bien y en mejorarlas si es posible [...]. Los resultados deben buscarse por medio de la comunicación y la discusión, nunca por medio de las órdenes y las reprimendas" (Badía y Bellido 1999: 47). 
productivas de la empresa y de los organizadores de la producción (Gaudemar 1991: 56): “La aplicación del principio de delegación aparece vinculada con la introducción [...] de fórmulas consideradas como potencialmente fructíferas para conseguir la interiorización imprescindible para el funcionamiento óptimo del orden productivo" (Dankbaar 1989: 108-119). Los trabajadores deberán asumir responsabilidades relacionadas con la regulación de su propia actividad laboral; y esto se realiza y justifica bajo el supuesto de que "la relación de trabajo dejaría de ser vista y vivida como un sometimiento alienante para transformarse en adhesión a una obra común en la que los trabajadores participarían más intensa y productivamente" (Castillo Mendoza, en Gaudemar 1991: 23):

Ya no sirve el ordeno y mando; el ordeno y mando te puede funcionar en un momento determinado, pero a ti lo que te interesa es que sin el ordeno y mando, sin decirle lo que tiene que hacer, que el tío te haga, lo difícil es que una persona haga lo que tú quieres que haga pensando que ha sido idea de él, y ese es el mejor sistema, no te tienes tú que colgar medallas: tú sabes que aquella medalla te corresponde a ti, pero si tú crees que aquel operario porque se lleve esa medalla, le tienes contento, va a hacer lo que tú quieras, algo más, y te va a resolver un montón de papeletas, dale la medalla a él. Aunque sea tuya, dásela a él [risas] (Director de Mecanizados. Empresa Berritzaile).

El gran problema es el problema humano, y a las personas, sobre todo cuando asumen una responsabilidad dentro de la empresa, hay que hacer que compartan iniciativas y que las asuman casi siempre como propias, que no se te vea ni tu sombra, aunque tú seas el promotor de esa iniciativa, para que la asuman con todas sus consecuencias. Si no, lo normal es que la gente interprete las iniciativas ajenas como interferencias, aunque sea la dirección general la que las proponga. Eso es siempre positivo, significa transmitir autoestima al que está en el escalafón inferior. (Gerente. Empresa Buruzagi).

Creo que hay un medio que es fundamental: la formación. La gestión de los recursos humanos, pero cuanto más sepa y más cualificada sea la persona, en principio mejor, pero la motivación ¿qué?, por muy formado que esté si no está motivado... La motivación, el sentirse ligado con el tema, que es importante, que sus opiniones valen: tú miras aquí todas las empresas que están teniendo éxito, han conseguido que las personas se motiven, con cien mil conceptos de producción que al final van a bajar los niveles de gestión al ámbito más cercano donde se producen los hechos, jcuidado! con los objetivos claros, pero que la decisión de alguna manera se despliegue con objetivos y con decisión, por ahí va el tema. Si tú consigues que unos señores en un taller pequeñito, o una mini-fábrica, y consigues que tengan claros los objetivos, que se gestionen, que resuelvan sus problemas, aquello funciona (Director Técnico de I+D. Empresa Buruzagi).

De hecho, los ingenieros que conciben los procesos de trabajo relacionan directamente la participación con la motivación de los operadores: 
motivados a implicarse en su trabajo, a movilizar esa inteligencia de producción tan valorada ahora empresarialmente, involucrándose en la consecución de los objetivos establecidos por la dirección, creando la noción de una especie de "comunidad industrial" (Smith 1989: 44-46; Mills 1948) basada en la comunicabilidad, la solidaridad, la integración y la cooperación (Linhart 1997: 30-32) ${ }^{11}$, en que capital y trabajo no están enfrentados sino vinculados por la supervivencia de la empresa, que es a la vez la supervivencia de los trabajadores y de los poseedores del capital:

El problema es el convencimiento de las personas, y al final era el ordeno y mando, para que lo terminen de ver. Y a veces te decían que ya sabían funcionar así, pero que no querían. Lo que necesitas es que los mandos estén bien formados, se supone que esos mandos están más preparados para adquirir esa formación, pero como no es así, puede ser un freno para que el conjunto de la empresa avance a los ritmos que uno quisiera. Se trata de demostrar que el trabajador participa en la empresa: lo que le estás diciendo es que en la empresa todos vamos en el mismo barco. Que se gestionen ellos y que esté implicado en el proceso. En definitiva, se les ha implicado más en todos los aspectos, en cuanto al desarrollo del producto, en cuanto a la calidad, en cuanto a la responsabilidad, se les ha responsabilizado más de aquello que fabrican (Director de Mecanizados. Empresa Berritzaile).

Y lo demás es trabajar, es ambiente, es comunicación, es calidad, al final comunicación y calidad quieren decir asunción de responsabilidad de gestión haciendo participar a la gente (Director Industrial. Empresa Zuzendu).

La mejora continua consiste en que estés en el taller, en hablar con los operarios, que sepas comunicarte con ellos, hacerles ver que aportan soluciones, poner en práctica sus ideas, que sientan que se les tiene en cuenta, que inicien la rueda de la mejora (Director de Calidad e I+D. Empresa Buruzagi).

Aparece así la fábrica, los centros de trabajo, como un laboratorio cultural de producción de sujetos, de modelado o acunación de los comportamientos que se consideran positivos productivamente por parte de las gerencias empresariales (Martín Criado e Izquierdo Martín 1993), que, en este caso, además de fabricar máquinas-herramienta, fabrican también trabajadores más implicados y más integrados respecto a las demandas de la dirección, al tiempo que pretenden simultáneamente fabricar un

11 "En nuestros programas de calidad participan casi todos nuestros empleados, los resultados tienen eficacia, no sólo en el aspecto monetario, sino también en el aumento del compañerismo, el entendimiento mutuo debido a las actividades comunes, en la satisfacción de los problemas solucionados y en el hecho de que el lugar de trabajo se convierta en un sitio agradable y cobre un sentido positivo (Gerente de Nissan Motor Co., en Senlle y Stoll 1995: 94; cursivas mías). 
nuevo orden en la producción, una nueva relación entre capital y trabajo que garantice que éste último "consienta" en su explotación en beneficio del primero, que facilite su conversión (desmovilizada) en trabajo efectivo.

Sin embargo, al considerar la participación no sólo como un nuevo concepto productivo, sino básicamente como un dispositivo de construcción del orden en la producción, una estrategia gerencial de control sobre la fuerza de trabajo, es necesario conocer hasta qué punto se consigue ese orden y cuáles son las bases sobre las que se articula el consentimiento de los trabajadores (su autoexplotación), ya que éstos pueden rechazar la gestión participativa de los recursos humanos, implantada por sus gerencias y desvelar así su contenido disciplinario y "productivista", como muestra la situación contingente de las empresas fabricantes de máquinas-herramienta analizadas en el trabajo de campo.

\section{EL MANTENIMIENTO DE ESPACIOS DE CONFLICTO: \\ LA AUTONOMÍA CLANDESTINA DEL TRABAJO HUMANO \\ Y LA FABRICACIÓN DEL CONSENTIMIENTO EN LA PRODUCCIÓN}

La gestión participativa de los recursos humanos, implantada en las empresas fabricantes de máquinas-herramienta estudiadas, tiene como finalidad última (re)construir un nuevo orden en la producción que permita explotar el trabajo humano sin conflicto. La participación y la aplicación de nuevos conceptos productivos llevaría a los organizadores de la producción a definir o crear sobre la tradicionalmente enfrentada posición de capital y trabajo un vínculo social o relacional entre ambos actores industriales que dé lugar a una especie de comunitarismo en la empresa" (Smith 1989), destacando, como hacía el propio taylorismo, la íntima armonía de intereses entre la dirección, la oficina técnica, el taller y los trabajadores. El capital y las direcciones empresariales acuñan un significado o sentido integrador en las relaciones industriales que pretenden transformar mediante la apertura limitada a la participación de los trabajadores en el proceso productivo y en sus puestos de trabajo.

Sin embargo, esa participación, que ha sido impulsada vertical y descendentemente por la dirección hacia el taller, está basada en un origen no-participativo al no intervenir en la definición y selección de los contenidos ni los trabajadores ni sus representantes sindicales, lo que ha conllevado que los propios operadores hayan interpretado estos nuevos dispositivos participativos (que no democratizadores en términos de reequilibrio de poder entre capital y trabajo) como una apuesta heterónoma y al margen de su propia situación subordinada en la producción. Por 
todo ello, los trabajadores en las cuatro empresas estudiadas, Buruzagi, Berritzaile y Zuzendu en Elgóibar, así como Eskulan en Vitoria-Gasteiz, al ser conscientes de que la participación en el puesto de trabajo es una transformación aimpuesta desde arriba" la aceptan con mayor escepticismo de lo que los organizadores de la producción esperaban:

Al final, lo único que hace la gerencia es dictarnos la lección y creemos que dictar la lección no es lo mejor: lo que tiene que haber es una mejor comunicación y relación con el taller, con el debate del propio trabajador, porque si nos dicen que el que mejor sabe cómo se hacen las cosas es el trabajador que está a pie de máquina o a pie de montaje, pues de ellos tienen que salir las mejoras, y lo mismo en la oficina técnica o en comercial: de ellos tiene que surgir la mejora, del debate entre ellos. Sin embargo, después de tantas charlas y cursillos, al final te dicen siempre cómo lo tienes que hacer y las mejoras que se te pueden ocurrir acaban en sus manos y te las obligan. Al final, en vez de que estemos todos más unidos con la empresa ha pasado que cada uno entiende el taller como sólo estar de sirena a sirena, es decir, el no encarnar con la empresa, cosa que antes había más encarnadura en la empresa, tú eras de Zuzendu o de Sigma, o de lo que fuera, hacía que la gente tuviera su importancia (Presidente del Comité de Empresa. Empresa Zuzendu).

Este escepticismo da lugar, y esto es lo relevante, a que los objetivos integradores y armonizadores de la dirección no se consigan articular de forma global y que la construcción del nuevo orden disciplinario de la producción sea menos sólida y esté menos anclada en la realidad de los talleres de lo que pretendían sus creadores.

De hecho, tanto los operadores de mecanizado como de montaje, como los representantes sindicales de los comités de empresa de estas cuatro compañias, mantienen y continúan subrayando la tradicional y acusada fractura organizativa entre el taller ("nosotros los operarios aquí abajon) y la dirección y sus departamentos técnicos de ingeniería de producción ("ellos los de arriban) como consecuencia precisamente del no cumplimiento de las expectativas participativas que los propios trabajadores desarrollaron cuando los organizadores de la producción les presentaron los contenidos pretendidamente democratizadores de "sus" transformaciones organizativas durante los años noventa. Los operadores consideran que después de entre cuatro y cinco años de implantación de los dispositivos de participación en sus puestos, su derecho a participar y transmitir sus impresiones e interpretaciones subjetivas sobre la organización del trabajo y del proceso productivo es muy limitado: la dirección no ha cumplido "Su parte del trato" tras la aceptación sin conflictos laborales y sindicales de las transformaciones organizativas de sus tareas, actividad y condiciones de trabajo. Los trabajadores han construido así colectivamente una 
interpretación sobre la participación y la dirección que puede ser resumida en que ésta, y la autonomía en la regulación de su actividad, queda siempre constreñida por la oficina técnica, que apenas admite o considera alguna de las sugerencias o modificaciones propuestas por el taller sobre el proceso de trabajo: la participación es sentida por los trabajadores como una táctica gerencial que tan sólo pretende aprovecharse de sus conocimientos sin recibir nada a cambio, ni en términos salariales, ni, sobre todo y como se explicará posteriormente, en relación al reconocimiento directivo de la pertinencia de los conocimientos del "obrero colectivo" y de los operadores como gestores inteligentes y cualificados de la producción.

Esta interpretación implica que, en estas empresas, junto al mantenimiento de la tradicional fractura organizativa entre dirección y taller, el trabajo humano se desvincule del pretendido carácter integrador de los dispositivos participativos, es decir, en lugar de que los operadores hayan desarrollado actitudes de implicación, colaboración y cooperación con los objetivos empresariales - tal y como pretenden los organizadores de la producción de estas compañías-, que hayan interiorizado ese nuevo orden productivo, aquellos son "aceptados" únicamente en su sentido disciplinario, como técnica de control sobre los comportamientos de los trabajadores, lo que ha provocado un efecto no intencional de las propias políticas participativas: el desvelamiento de los objetivos productivistas y de control de la fuerza de trabajo, lo que dificulta su aceptación y la construcción de ese nuevo orden en la producción.

El mantenimiento de esta fractura dio lugar a que los trabajadores profundizaran su tradicional autoidentificación como grupo o actor contrapuesto a la dirección y los ingenieros, a los que los operadores niegan su relevancia productiva al carecer de los conocimientos y experiencias de oficio sobre los procesos de fabricación que permiten obtener la producción: "los ingenieros nunca bajan a la suciedad y dureza del taller porque no saben qué hacer en él ni cómo fabricar las máquinas, son tan sólo 'latigueros' que vienen a exigir perfección y calidad en procesos que desconocen y que no pueden valorar" (Operador de montaje de tornos; Empresa Zuzendu). Esta fractura, que precisamente se ha profundizado con la gestión participativa de la calidad, demuestra claramente que su objetivo integrador y de fabricación de armonía no se ha producido, sino todo lo contrario, al hacerse evidente o haberse "desenmascarado" el origen no-participativo y disciplinario de estas políticas, cuyo limitado alcance ha traído consecuencias contrafácticas respecto a los objetivos que pretendían cumplir: no han eliminado el conflicto sino que éste se desarrolla en nuevos términos por parte de los trabajadores: 
Nosotros los trabajadores nos damos cuenta que hay unos escalones, siete escalones, que son inútiles. Que con dos valen, cinco sobran, es llenar arriba y reducir lo de abajo. Están completamente distanciados los de arriba, los batas y la mano indirecta que te be dicho antes; y la mano directa que es la que hace las máquinas, la que monta las máquinas, vulgarmente nos llaman 'borregos', y es un insulto al obrero que lleva igual cuarenta años, que es un profesional de su propio trabajo, y que venga un ingeniero que nunca ha estado en la máquina-herramienta, que esté un mes y te llame tonto: eso no se puede aguantar. Y eso se va acumulando, hasta que la gente se cansa y les dice que les den por culo. $Y$ eso es triste porque la empresa somos todos y respeto unos a otros, y no yo aquí y tú ahí abajo, no, tú en tu puesto de trabajo y yo en mi puesto de trabajo, todos somos iguales (Operador de grupo de montaje de tornos CNC. Empresa Zuzendu).

Con decirte que aquí en plantilla estamos 73 , y de los 73 que estamos 49 somos trabajadores y 24 empleados o mano de obra indirecta, al 50\%. Digamos que por cada trabajador hay media persona dependiendo de cada trabajador. Debería ser distinto y que hubiera por cada 5 o 6 trabajadores, una persona de oficina técni$\mathrm{ca}$, indirecta. No tienen sensibilidad con la clase trabajadora. Se preocupan mucho más de crear puestos de empleados en las oficinas que de crear mano de obra directa; si se crea mano directa se hace contrato tras contrato, de chavales jóvenes con estudios, valen mucho, mucho y están con los cojones aquí, porque si seis meses, otros seis meses, y están acojonados. La patronal abusa de los contratos de los jóvenes, cuando hay que potenciar a la juventud, para educarles en los aspectos del trabajo, de la máquina-herramienta, no se ve eso. Muy mala política llevan, hombre, para el patrón sí, el patrón se está forrando, los sueldos son mínimos para la juventud esa que vale, y para mí esto tendrá que explotar para algún lado (Comité de Empresa. Empresa Berritzaile).

Cuando viene un ingeniero o un técnico que te demuestra que tiene unas cualidades buenas y te dice que si esto es así o no, y tú ves que es una persona que sabe, pues se acepta; pero cuando es una persona que está pez y que te quiere implantar unas cosas y tú estás viendo que esas cosas que quiere implantar no son positivas para la empresa, porque tú tienes experiencia y llevas un montón de años aquí y algo sabes, pues no se puede aceptar, pero te obligan. Se queda lo que dice el trabajador en aguas de borrajas. Efectivamente en aguas perdidas (Operador de montaje de centros de mecanizado. Empresa Eskulan).

Sin embargo, es imprescindible explicar cómo se articulan simultáneamente las dos interpretaciones contrapuestas de dirección y operadores sobre los resultados de estos dispositivos de gestión participativa de los recursos humanos, sobre todo teniendo en cuenta que no se ha producido un rechazo explícito o una movilización abierta de los trabajadores y los sindicatos exigiendo su eliminación. Mientras para la gerencia su implantación y desarrollo ha sido un éxito al haber mejorado los criterios cuantitativos y de calidad de la fabricación de sus máquinas, para los trabajadores ha sido un fracaso al no haber dado lugar a una profunda participación y valoración de su actividad, constituyendo tan sólo una nueva 
disciplina de control. En otros términos, se analizará a continuación cómo, insertado en el marco del mantenimiento de este conflicto entre capital y trabajo, a pesar del rechazo que los trabajadores manifiestan a la forma en que se han implantado los nuevos conceptos productivos participativos, se ha mantenido y reforzado un consentimiento en la producción (Burawoy 1985) que da lugar a que, según las direcciones de estas empresas, los resultados empresariales hayan mejorado y se haya mantenido el orden productivo sin movilizaciones obreras de abierto rechazo.

El consentimiento en la producción no es más que el reverso teórico de la propia construcción del orden industrial mediante el cual el capital o las direcciones empresariales logran obtener trabajo efectivo de su fuerza de trabajo, del trabajo humano. Los trabajadores asalariados deben integrarse en la lógica disciplinaria del capital al venderle su fuerza de trabajo, quedando así subsumidos formal y realmente a las formas de organización del trabajo, diseñadas e impuestas por la dirección. La propia construcción de ciclos de disciplinas fabriles que controlaran la actividad de los operadores es consustancial a la historia de la empresa capitalista en una economía y sociedad de mercado, aunque, sin embargo, esas disciplinas han ido continuamente entrando en crisis cuando eran incapaces de garantizar o bien la eficiencia técnico-organizativa de la producción o la aceptación por parte de los trabajadores de esa disciplina: $s u$ consentimiento. El consentimiento supone, por tanto, que los trabajadores asumen o se adaptan a los dispositivos disciplinarios empresariales y sus objetivos, manteniéndose en sus puestos de trabajo produciendo, y en el caso que nos ocupa con los nuevos conceptos productivos produciendo más y mejor, a pesar de llegar a ser conscientes de su propia autoexplotación en beneficio del capital.

Esta reproducción del consentimiento obedece precisamente al propio mantenimiento del conflicto entre capital y trabajo, a esa autoidentificación del trabajo humano representado por los operadores como actor industrial (y cultural) contrapuesto a los organizadores de la producción. La fractura conflictiva entre los ingenieros (los batas) y los operadores (los buzos) ${ }^{12}$ es el recurso o dispositivo que, paradójica pero funcionalmente, permite el mantenimiento del nuevo orden productivo y que los traba-

12 En la totalidad de las empresas que han formado parte del trabajo de campo de esta investigación, el personal de la oficina técnica y de las diferentes ingenierías ("cuellos blancos") empleaban una bata para visitar o trabajar en los talleres, mientras que los operadores directos de montaje y mecanizado ("cuellos azules") utilizan obligatoriamente un mono o buzo, de ahí que, para los trabajadores, las diferencias entre estas prendas de vestir reflejen la distancia (social) y la fractura entre taller y gerencia, entre capital y trabajo, simbolizando el mantenimiento de su tradicional conflicto. 
jadores consientan la implantación de una gestión participativa de los recursos humanos de la que desconfían y que consideran insuficiente.

Este conflicto supone la actualización de una guerra contra la dirección por parte de los trabajadores desde una perspectiva del desarrollo de un fenómeno lúdico que canaliza el conflicto hacia el consentimiento de la producción: el juego de los operadores para demostrar su conocimiento cualificado frente a una ingeniería de procesos a la que consideran disfuncional o limitadamente útil para la producción. Los operadores niegan toda pertinencia a las instrucciones de trabajo y procedimientos establecidos por la dirección a través de la oficina técnica y de los ingenieros de producción, en los cuales, a pesar de las promesas directivas en la implantación de la gestión participativa, no se les ha permitido intervenir. Los operadores han desarrollado colectivamente, como obrero colectivo, un rechazo a las medidas participativas porque no han cumplido sus expectativas: porque no han supuesto otorgar relevancia productiva a sus conocimientos y experiencias, porque su inteligencia de producción queda limitada por las valoraciones de la ingeniería, que se reserva el derecho de establecer cuáles de las "mejoras continuas" sugeridas por los operadores de mecanizado y montaje son pertinentes, lo que cuestiona el discurso teórico empresarial sobre la centralidad y relevancia del factor humano. Todo esto constituye la base sobre la que los trabajadores construyen estrategias de enfrentamiento contra la dirección que, sin embargo, permiten a ésta obtener sus objetivos productivos y empresariales al estar orientadas a demostrar que los trabajadores son capaces de gestionar de mejor forma el proceso productivo sin respetar necesariamente los procedimientos establecidos por la ingeniería. El juego consiste en mejorar los resultados de fabricación movilizando su inteligencia de producción clandestinamente al margen de las normas, reglas e instrucciones diseñadas gerencialmente, intentando demostrar así los trabajadores su carácter de productores cualificados y expertos frente a unos ingenieros cuya acción consideran sólo dificulta el proceso:

Aquí tenemos ingenieros de calidad que nos dicen cuando las cosas están incorrectas y nos piden que las mejoremos. Sin embargo, yo creo que una persona cuando verifique una cosa, tiene que tener idea de esa cosa, porque si este ingeniero me dice que de aquí a allí tiene que haber una "rectitud" o que esté "a cero", y tú vas lo coges, lo miras y ves que está mal, y como operario le dices al ingeniero que yo no lo puedo dejar mejor y que me explique cómo hacerlo para dejarlo mejor: y normalmente el tío te dice que él no sabe cómo hacerlo, que no tiene ni idea, que te lo inventes tú. Lógicamente el que verifique la calidad tiene que ser una persona que si surge algún fallo o anomalía que sepa él cómo solucionar ese problema. Porque a mí me traigan un papel y yo mida esto y lo otro, pero yo no tengo ni zorra idea de cómo le quito estas dos décimas que sobran, 
y te dicen en ingeniería o en oficina técnica que hasta cuatro llegan pero no saben más, pues es un problema, y habrá que llamar a otro, cuando lógicamente esa persona es la que tendrá que saber hacerlo. Nosotros estamos bastante disconformes con eso (Operador de grupo de montaje de tornos CNC. Empresa Buruzagi).

Ellos sí, salen de ingeniero aeronáutico, y estupendamente, un sueldazo y no tienen ni puñetera idea de cómo es una fresa, ni un mandrino, ni una raspadora, ni una rasqueta, bueno, la rasqueta ya es de peones. $\mathrm{Y}$ una fresadora hasta que entran por la puerta y la ven [carcajadas colectivas]. Y esos son indispensables. Y no, aquí indispensables no hay ni uno, aquí en todo el edificio. Para que veas un ejemplo vivo, en la reestructuración que tuvimos de más de 90 personas, eran trabajadores manuales o directos. Del resto de empleados de oficinas, ninguno salió, todos se quedaron. Todos. Todos se quedaban. Encima a la hora mala, el primero es el trabajador porque parece que luego es fácil coger a otro por ahí, pero si es un empleado, eso ya se mira más escueto. Ahí es donde no estamos tampoco de acuerdo, ni lo hemos estado nunca. Eso grábalo bien, porque hay una falta de sensibilidad (Comité de empresa. Empresa Berritzaile).

Pero el dibujo que nos hacían en un principio, cuando nos vendieron la idea de que se iba invertir la pirámide, aquí no se invierte nada, aquí lo que se hace es acceder a que más gente esté más cerca de la dirección. Se hacen más jefes de equipo, empleados y postventa, parece que hay más gente cercana a dirección y menos gente cercana a los de la parte azul, pero de todas formas siempre hay un diferencial, no un abismo, pero sí una lejanía entre una gente y otra. En este sector la mano de obra directa tiene una cualificación suficiente como para seguir baciendo el trabajo sin dirección ni ingenieria, es decir, sin organización dirigida desde arriba, cada uno es capaz de hacer su trabajo, de ampliar a más y de acabar la máquina, otra cosa es ya diseño, ventas y todo eso (Operador de grupo de montaje de tornos CNC. Empresa Buruzagi).

La oficina técnica no viene nada más que cuando has terminado para montar, ahí sí que se falla mucho, porque la oficina técnica cuando hace una modificación se hace mal porque deberían tener más contacto con el taller, y te hacen una modificación en la que te cambian una pieza y luego tienes problemas con otros conjuntos de alrededor, eso se sigue dando. Hay un problema de comunicación, por ejemplo, esta mañana ha bajado uno de la oficina técnica porque una máquina metía ruido en el transversal, y no sabía nada, cuando desde que hicieron el cambio es cuando de siempre ha metido ruido, y el tío no sabía nada. Con lo que hay muchas deficiencias entre el taller y la oficina técnica. Ahí hicieron un cambio que no salió como esperaban y los trabajadores hemos dicho muchas veces que no está correcto, pero parece ser que la oficina técnica no quiere enterarse de ese problema (Comité de empresa. Empresa Eskulan).

A partir de esta acusada fractura entre ingeniería y taller, el trabajo humano "consiente" en incrementar su explotación y movilización en favor de unos objetivos productivos en cuya definición no se le permite participar como resultado de su autoconstrucción cultural y de identidad 
como grupo social relevante en la gestión del proceso de trabajo, diferenciado y opuesto al capital, que busca mejorar los procesos productivos para demostrar la ineficacia de las medidas gerenciales y de su propia ingeniería: el conflicto industrial se hace así funcional a los intereses del capital a través del juego de la guerra clandestina a la dirección.

En este proceso conflictivo pero funcional, los trabajadores emplean tres elementos fundamentales de su oficio e inteligencia de la producción: 1) sus conocimientos tácitos y experienciales, sus "tayloristamente" denostados métodos empíricos; 2) sus relaciones colectivas como grupo autoconstruido, es decir, la matriz relacional y cultural de vinculación entre los operadores como obrero colectivo; 3) los propios espacios de autonomía abiertos por la dirección con la implantación de los nuevos conceptos productivos. Estos son los recursos ("las armas") con los que se enfrentan a los procedimientos y reglas formalizadas, establecidas gerencialmente: subvirtiéndolas y manipulándolas, pero también aparentando seguirlas o mantenerlas, vencen a los ingenieros en su terreno, demostrando (y demostrándose a sí mismos) que el trabajo humano, los operadores, son el factor clave para la producción.

Por ejemplo, durante una de las múltiples jornadas de observación participante en el taller de montaje de máquinas-herramienta de la empresa Berritzaile, tres operadores de un grupo de trabajo enfatizaron al investigador el mantenimiento de la fractura entre ingeniería y taller, el conflicto latente entre los ingenieros organizadores de la producción y los operadores, al entregarle de manera clandestina el siguiente texto fotocopiado ("con esto [un folio mecanografiado] te explicarás mejor lo que te comentamos el otro día de que a los que estamos aquí en el taller los batas, los de arriba, no nos hacen ni caso, aunque ellos bajen y no sepan ni distinguir un tipo de máquina-herramienta de otro, pero por favor que no se sepa de donde lo has sacadon):

Cuentan las crónicas que en el año 1994 se celebró una competición de remo entre dos equipos, uno compuesto por trabajadores de una empresa multinacional USA en España y el otro por sus colegas de una empresa similar japonesa. Se dio la salida y los remeros japoneses se empezaron a destacar desde el primer momento. Llegaron a la meta y el equipo español lo hizo con una hora de retraso sobre los nipones. De vuelta a casa, la dirección se reunió para analizar las causas de tan bochornosa posición y llegaron a la siguiente conclusión:

"Se ha podido detectar que en el equipo japonés había un jefe de equipo y diez remeros, mientras que en el español había un remero y diez encargados, por lo que para el próximo año se tomarán las medidas adecuadas"

En el año 95 se dio de nuevo la salida y nuevamente el equipo japonés se empieza a distanciar desde la primera remada. El equipo español llegó esta vez con 
dos horas y media de retraso sobre el nipón. Dirección se volvió a reunir después del sonado rapapolvos de Gerencia para estudiar lo acaecido y vieron que ese año el equipo japonés se compuso nuevamente de un jefe de equipo y diez remeros, mientras que el español, tras las eficaces medidas adoptadas el año anterior, se compuso de un encargado, dos técnicos de calidad, siete ingenieros de producción y un remero, por lo que tras un minucioso análisis se llega a la siguiente conclusión:

\section{EL REMERO ES UN INCOMPETENTE}

En el año 96, como no podía ser diferente, el equipo japonés se escapó nada más darse la salida. La trainera, que este año se había encargado al departamento de nuevas tecnologías, llegó con cuatro horas de retraso. Tras la regata, y a fin de evaluar los resultados, se celebró una reunión de alto nivel en la cuarta planta del edificio, llegándose a la siguiente conclusión:

“Este año el equipo nipón optó una vez más por una tripulación tradicional, formada por un jefe de equipo y diez remeros. El español tras una auditoría externa y el reconocimiento especial del departamento de informática optó por una formación mucho más vanguardista y se compuso de un director técnico, tres ingenieros de producción con plus de productividad, dos auditores externos y cuatro vigilantes jurados que no quitaban ojo a un único remero al que habían amonestado y castigado quitándole todos los pluses por el fracaso del año anterior"

Ante el fracaso de esta formación en la trainera, se acordó tras varias horas de reunión que en la regata del 97 el remero sea una subcontrata externa, toda vez que a partir de la vigésimoquinta milla marina, se ha venido observando una cierta dejadez en el remero de plantilla que roza el pasotismo en la línea de meta.

\subsection{La "guerra" del taller contra la dirección: la subversión colectiva de los procedimientos formales de trabajo}

A través de las políticas participativas implantadas por las empresas estudiadas, sus direcciones e ingenierías de producción pretenden procedimentalizar detalladamente los procesos productivos y de trabajo para conseguir uno de los objetivos centrales de la racionalización taylorista: la reducción o eliminación de la fluctuación (humana) del proceso de trabajo a través del establecimiento de una norma, impidiendo su desviación. Sin embargo, la diferencia frente al taylorismo es que siendo ese fin de control inamovible, se reconoce y legitima ahora un cierto nivel de flexibilidad frente a esa fluctuación: se rechaza la idea de una "forma óptima" (best way) de organizar el trabajo y se apuesta por la creación continua de "mejores y mejorables formas" (better ways) de definición de ese proceso, es decir, de limitaciones continuamente incrementales de su fluctuación, en las que la participación de los operadores a través de la movilización de su inteligencia productiva es la nueva apuesta para lograr este objetivo. 
Sin embargo, los resultados finales de estos nuevos dispositivos participativos de racionalización no suponen más que una actualización de los procedimientos tayloristas y de la expropiación del conocimiento del taller hacia la oficina técnica, cuya práctica final consiste en el establecimiento de reglas formales que los trabajadores deben seguir obligatoriamente ("el procedimiento y las instrucciones de trabajo"). Estas reglas formales simbolizan y reflejan la capacidad excluyente y monopolística de los organizadores de la producción para concebir y dar contenido a los procesos de trabajo frente al taller ejecutante: son reglas impuestas y elaboradas por los organizadores de la producción para definir externamente los comportamientos permitidos a los operadores en el desempeño de su actividad; de esta forma, el proceso de trabajo está determinado por esas reglas formales de carácter explícito en que se definen con precisión los contenidos, cronología y naturaleza de las tareas de cada puesto (Terssac 1991: 84-85). Mediante estas reglas formales, la dirección reglamenta el trabajo y controla su ejecución dando lugar a una matriz de normas de producción y comportamiento que los operadores deben obligatoriamente seguir: para la dirección, el trabajo humano tiene necesariamente que respetar esas reglas, no subvertirlas ${ }^{13}$.

Precisamente, este es el origen de la fractura entre los departamentos de ingeniería y el taller, puesto que los primeros clausuran los contenidos del segundo sin que éste pueda participar e intervenir, al negársele su vinculación a la toma de decisiones productivas. Aunque con la implantación de los nuevos conceptos productivos se reconoce por parte de las gerencias la pertinencia productiva de los conocimientos del obrero colectivo, como se ha señalado, la decisión final de cómo deben movilizarse esos conocimientos y de cuáles son permitidos sigue quedando en manos de la dirección y sus reglas formales, con lo que la situación subordinada y marginal (al quedar en los márgenes) de los trabajadores sigue siendo un motivo de conflicto.

Al analizar en los terrenos contingentes donde se gestiona el trabajo, en los talleres de las empresas fabricantes de máquinas-herramienta estudiadas, se hace manifiesto que esa pretensión normalizadora y formalizadora de las direcciones —como base sobre la que construir el

13 "Las reglas impuestas son las elaboradas por el mando para controlar al grupo de ejecución, es decir, para intentar influir sobre sus acciones: se trata de definir, desde el exterior, el comportamiento del grupo de ejecución mediante instrucciones, procedimientos y reglamentos. Este dispositivo se basa en una separación entre el sistema de decisión, donde el mando se encarga de legislar el sistema físico en el que son situados los ejecutantes con la obligación formal de respetar los procedimientos" (Terssac 1991: 84). 
orden de la producción y el consentimiento de los operadores, su integración armoniosa no conflictiva - no se ha obtenido de forma total, sino que los trabajadores mantienen espacios de confrontación y lucha con la dirección, como consecuencia de su rechazo a las nuevas formas de organizar su actividad y al vínculo pretendidamente democratizador de la reestructuración productiva del sector durante los años noventa. Este rechazo se articula pragmáticamente mediante la subversión clandestina de esas reglas formales, no respetándolas o superándolas, de forma que los trabajadores - a través de los propios espacios de autonomía limitada y regulada "concedidos" por las gerencias- son capaces de apropiarse de la definición y gestión de su proceso de trabajo, más allá de los límites formales establecidos por estas últimas ${ }^{14}$. El objetivo final de este conflicto es la construcción de una identidad social propia por parte de los trabajadores, de su función y papel productivo, frente a la propia dirección y sus ingenierías, para demostrarse a sí mismos que poseen un conocimiento experto productivamente útil que, a pesar de los nuevos dispositivos expropiadores, sigue siendo clandestino y estando oculto para la dirección, al tiempo que les permite "sacar" la producción en mejores condiciones cuantitativas y cualitativas que si siguieran las reglas formales diseñadas gerencialmente. La subversión de éstas -a pesar de manifestar el mantenimiento del conflicto en el taller y el fracaso parcial de la «armonización" de las relaciones industriales perseguida por la "gestión participativa de los recursos humanos - permite, sin embargo, mantener el consentimiento de la producción de los trabajadores y la obtención de mejores resultados productivos, gracias a la propia guerra de los operadores contra la dirección. La lógica que construyen los operadores en este "juego bélico" supone afirmar que el respeto de los procedimientos diseñados e impuestos por la ingeniería de producción no es suficiente ni pertinente para lograr el resultado productivo deseado empresarialmente: los trabajadores consideran que las reglas formales de los ingenieros no sólo pueden ser incompletas, sino también incoherentes con las condiciones concretas del proceso de trabajo a las que ellos se enfrentan en el taller, lo que da lugar a que no sean útiles para gestionar su trabajo; los trabajadores movilizan sus conocimientos empíricos y colectivos para su-

14 "Para comprender las formas históricas reales del orden productivo capitalista es preciso analizar las complejas y variadas prácticas desarrolladas por los trabajadores para influir sobre las condiciones de su activación laboral, en la medida que permiten dar cuenta de los entrecruzamientos, modificaciones, tránsitos y crisis que se dan dentro, y entre, los grandes ciclos de las técnicas disciplinarias" (Castillo Mendoza, en Gaudemar 1991: 14). 
perar estas limitaciones que les imponen las reglas formales de la dirección, manipulándolas o subvirtiéndolas (Terssac 1995: 128-141).

De hecho, esta paradoja del carácter funcional para los intereses empresariales del mantenimiento del conflicto industrial entre taller y dirección se explica por la propia movilización de la inteligencia de producción de los trabajadores: éstos, frente a las reglas formales de la dirección, diseñan, crean y practican formas alternativas de desarrollar el proceso de trabajo, crean reglas informales que, por un lado, les permiten obtener la producción en mejores condiciones de tiempo, cantidad y calidad que si siguieran las reglas formales obligatorias, que son externas e impuestas, al tiempo que, por otro lado, les permiten también mantener su autoidentificación de gestores expertos y cualificados del trabajo, al ser capaces de demostrarse que sus métodos empíricos son mejores que los propuestos por la dirección y la ingeniería. Es la construcción de las propias reglas informales lo que fundamenta al colectivo de trabajo y su lucha por incrementar sus competencias y su autonomía (su soberanía productiva sobre el proceso): "lo que fundamenta un colectivo es su constitución como actor social capaz de movilizar recursos individuales y combinar acciones independientes" (Terssac 1991: 96), facilitando, en este caso, la elaboración de una acción común de oposición a la dirección y a su ingeniería (Terssac 1995: 153-189) ${ }^{15}$.

Estas reglas informales pueden suponer desde la modificación autónoma y clandestina de las instrucciones y procedimientos de trabajo, pasando por complementar partes inexistentes o necesarias de los propios procedimientos con nuevas operaciones no consideradas por la ingeniería, hasta la sustitución de un procedimiento por otro mejor adaptado a la situación real y contingente de los puestos de trabajo y sus incidentes: "pretenden tener presente el contexto real de trabajo y adaptar las instrucciones a esas condiciones efectivas e incluso cambiarlas en caso de inadecuación" (Terssac 1991: 93). De hecho, la creación de "métodos empíricos optimizadores" es el fin de las políticas participativas de estas empresas, pero siempre que puedan ser controlados, expropiados y formalizados por la dirección, mientras que estas reglas informales construidas por los operadores desde su conflicto contra la dirección son mantenidas en la clandestinidad: evitan que sean detectadas y conocidas por la dirección, que queden integradas en un nuevo procedimiento (escrito y

15 La informalidad o clandestinidad de estas reglas creadas por el obrero colectivo supone la producción, el intercambio, la socialización y el perfeccionamiento de los saberes, los conocimientos y las prácticas de los trabajadores, lo que les permite gestionar los incidentes y disfunciones cotidianos de la actividad productiva (Linhart 1990: 38). 
documentado) por el dispositivo de "mejora continua" controlado gerencialmente, de manera que tan sólo ellos las crean y gestionan, mejorando el proceso de producción al margen de las ingenierías de producción y su pretendido "saber experto". Para los trabajadores saber o ser conscientes de que sus reglas informales clandestinas son productivamente más pertinentes que las de los técnicos de la oficina, que son capaces de crearlas autónoma e "ilegalmente", que son eficaces y eficientes, y que demuestran la posesión de un conocimiento experto útil para la empresa, es la "recompensa social, frente a las expectativas no cumplidas por unas políticas participativas que no han desarrollado prácticamente aquello que las direcciones dijeron implantar. Los trabajadores emplean esos márgenes participativos como fundamento para la resistencia ante la dirección, para subvertir las reglas formales y poder así mantener su identificación como grupo relevante que, a través de sus acciones informales e ilegales, permite que la producción salga adelante y "vencer" a los ingenieros en su propio terreno (Terssac 1991: 94). Para los operadores de taller, sus reglas informales no son más que modos operativos de actuación que les permiten obtener el resultado productivo que se les exige por caminos diferentes y más eficientes que los propuestos formalmente por la dirección: su desviación frente a la norma permite obtener la producción y "demostrar la vanidad e ilegitimidad de los 'señores de los despachos'" (Linhart 1990: 40). Los trabajadores elaboran así una lógica de acción común, basada en la resistencia frente a la procedimentalización y la oposición respecto a la dirección (Terssac 1991: 96); un conflicto que garantiza el consentimiento en la producción y la obtención de los intereses empresariales, pero que, al mismo tiempo, evidencia el fracaso de la integración comunitaria pretendida por los organizadores de la producción con sus políticas participativas de los recursos humanos.

En definitiva, en cuanto a la actividad real y efectiva (la situación real de trabajo), lo que es prioritario destacar es la forma en que se produce esa regulación social y colectiva entre los operadores: estos gestionan de forma autónoma el proceso de trabajo tomando sus propias decisiones sobre qué elementos son prioritarios en un momento dado del montaje o mecanizado, sobre su distribución y sobre la gestión de los propios procedimientos formalizados (el trabajo prescrito o la tarea) por la oficina técnica (métodos) y de calidad. Los operadores consultan unos con otros, se ayudan en las tareas, definen y transmiten nuevas posibilidades de resolver los problemas para el mecanizado de una pieza o el montaje de un conjunto. De hecho, la pretensión de la ingeniería de producción es que esos métodos queden endurecidos en los amanuales de procedimiento", que son, por tanto, reglas formales o imperativas para la realización 
del trabajo. El trabajo de campo ha permitido establecer precisamente que la regulación social que los operadores construyen sobrepasa los objetivos que la dirección pretende con el reconocimiento de esa iniciativa colectiva de los grupos de trabajo: para la dirección, la autonomía que se persigue desarrollen los operadores está limitada por el seguimiento y respeto de los contenidos de los procedimientos formales (autonomía limitada o controlada por una ejecución coherente con las reglas formales), es decir, por el mantenimiento y respeto de las reglas formales establecidas (Terssac 1995: 63-64). Lo fundamental es que esos procesos de regulación llevan al colectivo de trabajo a la construcción de reglas informales e "ilegales" (respecto a la dirección) que no necesariamente respetan los manuales de procedimiento: la infracción continua y consciente de las reglas prescritas les permite realmente obtener la producción en menor tiempo y en mejores condiciones. Los operadores consiguen ampliar esa autonomía controlada no sólo como recurso productivo útil, sino como una forma de mantener su identidad frente a la dirección, a la que no otorgan ningún conocimiento relevante en el diseño de los procesos, puesto que tan sólo infringiendo sus normas son capaces de mantener la producción.

Se establece así un juego de guerra industrial entre los trabajadores y los ingenieros, de manera que los operadores de taller emplean la autonomía reconocida por la dirección para crear sus propios métodos al margen de las instrucciones de los ingenieros, a los que finalmente no reconocen su pretendida "autoridad" en la definición de los procesos de montaje y mecanizado: la creación de sus propios y mejores métodos supone en términos de trabajo real que los trabajadores rechazan los limitados y escasos contenidos participativos de las políticas gerenciales, que demandan incrementar su participación y que la ingeniería practique efectivamente su discurso teórico de que "los operarios son los que conocen el proceso y los que deben tener la responsabilidad de controlarlo, trabajando conjunta y cooperativamente entre el taller y los departamentos técnicos" (Director de Recursos Humanos. Empresa Buruzagi).

A continuación se presentan tres casos de regulación informal y productiva del proceso de trabajo por parte de los operadores entendidos como un proceso de resistencia y conflicto (Terssac 1996: 31-32), como “juegos contra la dirección", que se observaron en las estancias en los talleres de mecanizado y montaje de las empresas Zuzendu, Buruzagi y Berritzaile y en los que se hace evidente cómo la fractura entre taller e ingeniería es la base para la movilización colectiva de los operadores, de manera que enfrentándose a las reglas formales de la dirección, completándolas u "optimizándolas" con la aplicación autónoma de su inteligencia 
de producción, mantienen su consentimiento (el nuevo orden en la producción), intensifican su propia explotación, y obtienen los resultados esperados en las condiciones impuestas por los propios organizadores de la producción, haciendo funcional para éstos el propio conflicto entre capital y trabajo, al tiempo que los trabajadores reafirman su autoidentificación como obrero colectivo ${ }^{16}$ experto frente a los conocimientos de la dirección:

\subsubsection{Mecanizados: La formación ailegal" en programación de un} operador de máquinas $\mathrm{CNC}$

La mayoría de los trabajadores de mecanizado de la empresa Zuzendu conducen máquinas de control numérico por ordenador (CNC) en puestos de trabajo semi o descualificados en que tan sólo pueden corregir muy limitadamente ciertos parámetros de los programas de la máquina, quedando confinados a ser meros alimentadores de piezas. Pues bien, en la empresa Zuzendu estos operadores tienen probibido acceder a los programas del control numérico más allá de las correcciones que se les permiten realizar, lo cual les lleva a que, cuando surge algún incidente en el funcionamiento de la máquina, tengan que recurrir o a su encargado o a la oficina de programación, con los inconvenientes productivos de parada de las máquinas, de la producción y de desaprovechamiento de los conocimientos experienciales de esos operadores, que habitualmente procedían del manejo cualificado de máquinas convencionales manuales. La regla formal se resumía en: "tú no toques ahí [al control numérico], que sacas chatarra" (Operador de torno CNC; empresa Zuzendu); es decir, en establecer un principio taylorista por el que -al considerarse al operador como una fuente de perturbaciones de la máquina- se proscri-

16 Este carácter colectivo del trabajo humano supone que los operadores comparten y socializan entre ellos pericias grupales que conllevan una forma de aprendizaje a través de la acumulación y difusión de experiencias de trabajo, que sirven para construir un conocimiento colectivo que impregna las representaciones funcionales o imágenes operativas de cada miembro sobre el proceso productivo. La inteligencia de producción poseída por los trabajadores es producto de su historia, de sus prácticas pasadas (de su babitus), asegurando que éstas se mantengan activas en el presente en la forma de esquemas de percepción, de pensamiento y acción que les permiten producir con más seguridad que siguiendo las reglas formales y las normas explícitas de los organizadores de la producción (Troussier 1987). "El equipo que trabaja y diariamente con una comunicación cara a cara de unos con otros [...] es literalmente una familia en el trabajo que disciplina a sus miembros y toma decisiones conjuntamente en el espacio inmediato de trabajo y puede afectar el flujo de producción" (Weir 1973: 177). 
be la recualificación de ese tipo de operadores. Sin embargo, durante la observación participante en uno de los talleres de mecanizado de esta empresa se presenció que un operador de torno $\mathrm{CNC}$, que tan sólo podía formalmente editar el programa, no sólo corregía más parámetros y líneas de las que le establecían sus instrucciones de trabajo, sino que incluso reprogramaba autónomamente el programa recibido de la oficina técnica y lo adaptaba a las situaciones contingentes y variables que enfrentaba tanto el propio operador como el estado de la máquina. Sin duda alguna, este operador estaba infringiendo la regla formal, la norma, establecida por la ingeniería de producción. Las razones de esta subversión de la regla se centraban en que así el operador podía:

a) Reducir su descualificación al haber aprendido clandestinamente a programar el CNC, lo que tenía expresamente prohibido

b) No tener que depender de otros sujetos para gestionar cualificadamente los incidentes de la máquina

c) Poder volver a emplear sus empíricos conocimientos convencionales (alteración de velocidades de avance y giro, establecimiento de número de amarres óptimos...) para obtener en mejores condiciones de producción las piezas (normalmente ejes de los cabezales de tornos) que se le encomendaban

d) Aumentar efectivamente la amplitud de sus tareas (de su trabajo prescrito) y los márgenes de acción de su actividad

e) Y, sobre todo, recuperar una posición "experta" en la gestión colectiva del proceso de trabajo.

Ahora bien, al intentar conocer cómo este operador fue capaz de formarse clandestinamente en la programación del control numérico de su torno se hizo evidente que no sólo infringía la regla formal sino que, y esto es lo fundamental, la sustituía mediante la creación de una regla informal ilegal que le permitió la adquisición de esa nueva cualificación. Este operador veterano había construido consensuada y colectivamente esa regla informal con otro operador novato: éste, que sí poseía cualificación en programación de $\mathrm{CNC}$, enseñaba a lo largo de la jornada de trabajo al veterano a programar su máquina, a cambio de que este último le transmitiera al "joven aprendiz" conocimientos avanzados de procesos que le permitieran optimizar los amarres de las piezas (hacer el mayor número posible de operaciones a la pieza en cada amarre), la selección de las herramientas más adecuadas para mecanizar diferentes materiales, velocidades de avance y giro que facilitaran su trabajo y sus resultados; en definitiva, a definir y planificar de forma más eficiente sus operaciones. Esta regla informal les permite superar colectivamente (al obrero colectivo) la norma formal de la ingeniería, centrada en que el joven novato puede (y debe) aprender del veterano, pero éste no tiene permitido 
gerencialmente aprender conocimientos de programación, lo que, sin embargo, hace eilegalmenten: supera así la prohibición de la dirección -lo que le ha permitido no tener que parar la producción de la máquina para recurrir a los programadores de la oficina ante cualquier incidente en el torno CNC- aumentando ilegalmente el contenido de su tarea, y logrando mejorar el tiempo de producción y la calidad en la que fabrica las piezas, lo que finalmente es beneficioso para la empresa. Infringiendo la prohibición (subvirtiendo la regla formal), la empresa obtiene de forma no intencionada dos operadores que mejoran sus conocimientos y gestionan de forma más productiva sus procesos de trabajo, mientras que si hubieran seguido las reglas impuestas por la dirección, ésta desaprovecharía los recursos de su mano de obra.

Este juego conflictivo de creación de una regla informal, que sustituye las prescripciones formales de los organizadores de la producción, permite simultáneamente la recualificación clandestina de un operador organizativamente descualificado y que, gracias al incremento de sus conocimientos de programación, éste sea capaz de producir en mejores condiciones y obtener los resultados productivos deseados por la dirección: tan sólo sustituyendo "ilegalmente" la estrategia tecnocéntrica de ésta, es decir, recualificando clandestinamente el puesto de trabajo de este operador de máquinas $\mathrm{CNC}$, se consiguen los objetivos de producción pretendidos por los organizadores, cuyas reglas formales son en este caso un impedimento para el mantenimiento fluido del proceso de trabajo ("que la máquina no se pare y que la máquina produzca lo más eficientemente posible"), lo que es "corregido" por la regulación colectiva autónoma del trabajo humano del taller, que recupera así "invisiblemente" su papel cualificado en la gestión de la producción.

\subsubsection{Montaje: La mejora de la calidad más allá del procedimiento formal}

En el montaje de los cabezales de las máquinas-herramienta -el conjunto que da movimiento a la herramienta, que incide sobre la pieza para mecanizarla en el caso de las fresadoras fabricadas por la empresa Buruzagi-, al igual que en los demás puestos de trabajo, una de las nuevas funciones de los montadores es garantizar que este componente estratégico, una vez montado, cumple los requisitos de calidad establecidos en el procedimiento y las instrucciones de trabajo de esos puestos, ya que si no es así los operadores deberán desmontar el cabezal y revisarlo hasta que cumpla esos parámetros, lo que se controlará a continuación mediante la revisión de las "fichas de calidad" firmadas personalmente por los operadores. 
A partir de aquí, la regla formal diseñada por la ingeniería de producción de la empresa Buruzagi en la procedimentalización de las operaciones de montaje establece que para que un cabezal "esté conforme" el ruido producido por su funcionamiento no debe superar los ochenta decibelios ${ }^{17}$, de manera que, siempre que esté por debajo de esa cifra, los trabajadores habrán conseguido los objetivos de calidad gerenciales. Sin embargo, en este caso, los operadores crean colectivamente una nueva regla informal que endurece y complementa los criterios de calidad establecidos por los ingenieros. Las máquinas fabricadas por Buruzagi (tornos y rectificadoras) recibían quejas de sus compradores por un exceso de ruido en sus cabezales - a pesar de cumplir la normativa de nivel sonoro-, lo que implicaba la existencia de un error de diseño de ingeniería en la articulación mecánica de los componentes del cabezal y en las instrucciones de su montaje. Ante esto los trabajadores decidieron superar la regla formal y no sólo controlar a través de un sonómetro que el cabezal produce un ruido por debajo de los $80 \mathrm{~dB}$, sino que definieron un procedimiento de montaje diferente al recogido por las instrucciones de la dirección, de manera que tan sólo consideran un cabezal conforme si, además, "suena" de una determinada manera, que les indica que está bien montado y fabricado.

Es decir, han conseguido que esa nueva forma de montar los componentes, que los propios trabajadores han creado, reduzca el problema productivo detectado por los clientes, de manera que el cabezal cumpla tanto la norma como la demanda de los compradores; de hecho, si ese cabezal no "suena" como los trabajadores establecen que debe sonar, lo desmontan, revisan y corrigen hasta que obtienen en su funcionamiento ese sonido, todo ello a pesar de que cumpla el parámetro sonoro establecido por la dirección. De esta forma, tan sólo creando autónomamente una regla informal que, en este caso, complementa las deficiencias del procedimiento formal de trabajo, los operadores garantizan la obtención de sus objetivos productivos en mejores condiciones que si tan sólo siguieran la regla formalizada de calidad. Mientras que los ingenieros parecen incapaces de diseñar un cabezal sin problemas, los trabajadores, informal y clandestinamente, optimizan los resultados empresariales (la

17 Ochenta decibelios es la intensidad sonora máxima permitida reglamentariamente a una máquina en funcionamiento en la legislación sobre prevención de riesgos laborales, nivel por encima del cual se establecen medidas obligatorias de seguridad e higiene industrial. Parece interesante destacar, sin embargo, que, aunque máquinas individuales estén por debajo de esa cifra, su funcionamiento conjunto hace que ésta pueda superarse: la conformidad de las máquinas individualmente consideradas puede ocultar su peligrosidad conjunta. 
calidad) aplicando su inteligencia de producción al margen de lo establecido por los departamentos técnicos. De hecho, el procedimiento informal para la obtención del "sonido correcto" establecido por los trabajadores es resultado de su propia experiencia, del desarrollo de un sofisticado conocimiento práctico del trabajo real de este proceso particular de producción (Grzyb 1981: 471); inteligencia de producción que es parte fundamental de su cultura obrera, que tan sólo movilizándola de un modo clandestino les permite "sacar" la producción cualificadamente (Terssac 1995: 113-151) y enfrentarse resistiendo a las decisiones de los organizadores de la producción (la dirección y su ingeniería). Al mismo tiempo, mantienen oculto ese procedimiento informal, evitando que quede documentado en las instrucciones de trabajo normalizadas, de manera que los trabajadores pueden decidir autónomamente cuándo mejorar la calidad subvirtiendo la regla formal o cuándo "culpar" de los problemas de los cabezales al seguimiento del ineficaz método de trabajo establecido por la ingeniería, todo ello como recurso de enfrentamiento con la dirección.

\subsubsection{Aseguramiento de la calidad: La subversión de la norma ISO-9000}

Desde mediados de los años noventa, las empresas más innovadoras del sector de fabricantes de máquinas-herramienta han desarrollado intensas políticas de aseguramiento de la calidad de sus procesos de diseño, fabricación y comercialización, mediante la implantación de las normas internacionales de la familia ISO-9000. Las normas ISO-9000 han dado lugar a un amplio proceso de procedimentalización exhaustiva de las tareas y actividades de los operadores, de manera que, para poder asegurar que desarrollan su trabajo con criterios de calidad, deben seguir obligatoriamente las instrucciones de trabajo definidas en los procedimientos diseñados. Pues bien, esas instrucciones de trabajo funcionan como reglas formales establecidas por la ingeniería que los trabajadores deben seguir al pie de la letra, es decir, deben respetarlas para obtener los objetivos de producción. En el caso del taller de montaje de la empresa Berritzaile se observó que, en uno de los grupos de montaje de fresadoras $\mathrm{CNC}$, una pareja de operadores en múltiples ocasiones decidía no seguir los procedimientos de trabajo y resolver los problemas de producción y las "no conformidades" $^{18}$ que detectaban en algunas de las piezas que debían

18 El "control de los productos no conformes" (apartado 4.13 de la norma ISO9000) supone asegurar que los productos o componentes de fabricación con alguna anomalía no se utilizan o instalan por inadvertencia, definiendo a quién corresponde 
montar mediante una regla informal que sustituía ilegalmente las instrucciones obligatorias de la ingeniería. El procedimiento formalizado por la dirección establecía que, cuando un operador descubría que una de las piezas a montar tenía algún error (normalmente de mecanizado) que impedía su ensamblaje o el cumplimiento de los criterios de calidad, el propio operador debía:

1) Informar primero a su jefe de equipo y discutir el problema

2) A continuación debía avisar al encargado del taller de montaje para decidir la sustitución de la pieza no conforme

3) Lo que implicaba solicitar una nueva pieza con esas características al almacén, en el caso de que hubiera suficientes piezas almacenadas

4) O encargar una nueva pieza a los talleres de mecanizado, en este caso como consecuencia de las políticas justo a tiempo generalizadas en las empresas consideradas que hacen que tan sólo se mantengan las piezas "justas" para la producción de alrededor de una semana.

En principio, el operador no podía tomar formalmente la decisión de aceptar o rechazar esa pieza "no conforme", sino que dependía de toda esa "cadena de mando" para continuar con su trabajo, lo que podía suponer que, en el peor de los casos, fuera necesario esperar varios días hasta que el almacén obtuviera una nueva pieza conforme o hasta que se mecanizara una pieza sustituta, lo que puede implicar retrasar durante varias jornadas el montaje final de esa máquina que requiere la pieza problemática. Ante esta posible situación que se origina por la obligatoriedad de seguir esos pasos procedimentales en el caso de la aparición de una pieza no conforme, esta pareja de operadores de montaje creó una regla informal que suponía no respetar, subvertir y rechazar esas medidas imperativas de gestión de las no-conformidades: cuando alguno de ellos detectaba una pieza con un error de mecanizado, analizaba sus efectos sobre el resto de montaje (ausencia de tolerancias correctas, acabado

examinar esos productos y quién debe decidir su destino. Ante la aparición de una "no conformidad" interna (descubierta en la empresa) o externa (descubierta por el cliente), las empresas fabricantes de máquinas-herramienta estudiadas identifican el componente problemático con una pegatina que indica el contenido de la no conformidad o el criterio incumplido, si ese componente debe ser definitivamente rechazado (pegatina de color rojo) o si puede ser reprocesado y corregido (pegatina de color amarillo) para ser aprovechado una vez subsanado su error (todos los productos conformes o correctos se identifican con una pegatina de color verde). El objetivo último de este control de productos no conformes es detectar errores en el proceso de trabajo y la búsqueda continua de mejoras para corregir su posible reaparición y para prevenir nuevas no conformidades (apartado 4.14 de la norma ISO-9000: *acciones correctoras y preventivas") (Badía y Bellido, 1999: 68-69; AENOR, 1994). 
superficial incorrecto, medidas geométricas inexactas...), consultaba con su compañero, y tomaban la decisión de o bien recuperar ellos mismos la pieza o, por el contrario, seguir el procedimiento y avisar a su jefe de equipo; en la mayoría de las ocasiones, ante la aparición de un problema de mecanizado de la pieza, estos dos operadores lo solucionaban llevándose ésta a una "célula auxiliar" con viejos tornos, fresadoras y rectificadoras, donde volvían a mecanizar rápidamente la pieza no conforme, dejándola en las tolerancias necesarias para seguir el montaje en tan sólo unas decenas de minutos, evitando así el largo proceso temporal de consultar a su jefe de equipo, al encargado, al almacén, etc., con lo que se evitaba una amplia demora en la producción, tomando informal e «ilegalmente una decisión productiva que está expresamente proscrita en los procedimientos de trabajo establecidos por la dirección ${ }^{19}$ :

Mira, nosotros tenemos que seguir un plan de aseguramiento de la calidad. Si yo recibo una pieza para el montaje que, aunque lleva la pegatina de aceptada, está mal, tengo que seguir el procedimiento: comentárselo a mi jefe de equipo, éste al encargado del taller, ir al almacén a por un repuesto o enviársela al proveedor para que mande una pieza en condiciones: total de dos a tres días sin la pieza, o incluso cinco. ¿Qué es lo que hago para asegurar la calidad? Cojo la pieza mala, la reviso, me voy al torno [célula auxiliar] o a la fresa, le pego un repaso y ¡zas! en 20 minutos o media hora sigo montando y no estoy parado tal cantidad de días. Si hiciera lo que me dicen, la calidad me pararía. Eso sí, después en dirección piensan que todo sale sólo con la ISO esa, cuando somos nosotros los que

19 De forma gráfica, los trabajadores, apropiándose de la capacidad de decisión expresamente otorgada al encargado del taller de montaje sobre el destino de una pieza no conforme, hacen que un amplio número de piezas a rechazar (identificadas con la pegatina roja) acaben siendo rápidamente recuperadas (adquieran la pegatina verde) y reintroducidas en el proceso productivo, sin necesidad de esperar que se les permita por parte del encargado autorizado para ello que reprocesen esas piezas (otorgándoles previamente una pegatina amarilla): estos trabajadores no sólo actúan silegalmente", sino que no respetan la "cadena de autoridad" mediante su movilización autónoma, reflejando la dinámica del conflicto y la lucha por el control efectivo del proceso de producción: «La calidad está funcionando aquí en que las cosas vienen aceptadas. Pero el que venga aceptado no quiere decir que esa pieza viene en condiciones, porque te podemos decir que vienen piezas aceptadas y vas a montarla y resulta que no están en condiciones. Lógicamente si una calidad pone que está aceptado es que entra dentro de esas verificaciones y de esa calidad que tiene que venir. ¿Qué has conseguido en ponerle el aceptado, si esa no está en condiciones por las circunstancias que sean?. La calidad es muy bonita pero hay que saber aplicar ese papel. Tú puedes tener los papeles en regla, con los requisitos que te pide el cliente, pero luego lo que pone esos papeles de calidad no sé da, porque hay algún fallo» (Operador de grupo de montaje de fresadoras CNC. Empresa Berritzaile). 
no haciéndoles caso podemos terminar la máquina en el tiempo, si no ¿de qué? (Operador de grupo de montaje de fresadoras CNC. Empresa Berritzaile) ${ }^{20}$.

Sin embargo, el desarrollo de esta regla informal y el no respeto de las instrucciones de trabajo permite a los operadores, por un lado, mantener un espacio clandestino de movilización autónoma de sus conocimientos y pericias (Reynaud, en Terssac 1995: 11-18), así como reafirmar que éstos últimos y su inteligencia de producción son más efectivos para gestionar el trabajo y las tareas impuestas por la ingeniería de procesos que las propias instrucciones diseñadas por ésta, mientras que, por otro lado, la empresa obtiene su producción con menores contratiempos y problemas gracias a que sus trabajadores no respetan la normalización y procedimentalización desarrollada a través de la interpretación de esta empresa sobre las normas ISO-9000 implantadas, que en este caso funcionan como un dispositivo entorpecedor del trabajo de los operadores y de su efectividad. Si los operadores siguieran en este caso las instrucciones obligatorias del aseguramiento de la calidad tendrían que retrasar la producción, mientras que sus conocimientos y comportamientos clandestinos permiten solventar las rigideces impuestas por la aplicación restrictiva de la ISO-9000 y mantener la fluidez del proceso interrumpida por ésta última: "La documentación del Sistema de Calidad será cumplida y utilizada en la medida en que los trabajadores perciben que les soluciona

20 Aparece simultáneamente una acusada desconfianza sobre las políticas de aseguramiento de la calidad entre los operadores, que las consideran más una actuación de imagen comercial hacia el exterior que una verdadera preocupación por la mejora de los procesos productivos, en la que su experiencia e inteligencia de producción deberían jugar un papel relevante en la realidad (y no sólo en los discurso gerenciales): "En calidad, es el trabajador, es uno mismo, el que tiene que hacer esa calidad, pero a la empresa no le interesa la formación profesional de los trabajadores. La calidad es formación profesional, máquinas obsoletas poner nuevas, y es que el operario tenga formación y que la máquina esté bien. La calidad en resumidas cuentas es que el operario esté a gusto, que esté formado, que se le dé para que se forme, y de ahí empezaremos a hacer calidad. Pero mientras esas circunstancias no se den, no bay calidad y si no se dan: pasamos de todo (Comité de empresa. Empresa Berritzaile).

"En estos años se está hablando mucho de la calidad, en la que todos estamos de acuerdo, pero la calidad no es un papel, y si tú entras en cualquier empresa de hecho, la calidad estamos viendo que se compra, tú verás en cualquier empresa que la calidad es la ISO-9001, el $80-90 \%$ de esas empresas su calidad, por experiencia, es dinero lo que supone, es dinero, porque luego entras en profundidad y miras ese proceso, y ves que la calidad no se lleva como está explicado en este papel, pero el papel ese cuesta dinero y hay que pagarlo y ya tienes la calidad. Ese proceso empieza por arriba y luego termina abajo: los trabajadores no participamos de ninguna manera" (Operador de grupo de montaje de tornos. Empresa Buruzagi). 
los problemas reales. Por el contrario, si lo perciben como una imposición de la norma, o de la misma dirección, sin que se lleguen a ver las ventajas de su utilización, su implantación y mantenimiento están condenados al fracaso" (OMPES 1998: 24):

Quieren que mejoremos la calidad rellenando papeles en vez de con mejores herramientas y materiales, como les decimos a los de la oficina de calidad. Yo, desde luego, no pienso rellenar nada; ya le dije a los batas, "como no rellenes tú los papeles: a mí me pagan para montar máquinas, no para escribir tonterías" (Operador de grupo de montaje de fresadoras CNC. Empresa Berritzaile).

Estuve en un curso de formación sobre la ISO-9000 esa: lo único que aprendí fue que la 9001 es fabricación, la 9002 es montaje y la 9003 se refiere al almacén, o eso creo. No me sirvió para nada. Que me den herramientas buenas y verán cómo sube la calidad. No tienen ni idea y no nos hacen caso a los obreros de taller, que casi nacimos con una lima y una máquina bajo el brazo (Operador de grupo de montaje de tornos CNC. Empresa Zuzendu).

Respecto a la calidad, lo que es necesario es mejorar la maquinaria para conseguir más rápidamente las piezas, pero tampoco se nos consulta ni se nos pide nuestra opinión, que después de tantos años manejándolas digo yo que sabremos algo del tema: se traen máquinas que los que las manejamos no creemos que sean útiles, se rechazan y desechan otras que con poca inversión se pueden mejorar mucho y aprovecharlas, pero no se nos comunica nada. Nos dicen que apliquemos el manual de calidad y ya está, eso es la calidad (Presidente Comité de Empresa. Empresa Zuzendu).

En definitiva, todas estas experiencias muestran que el alcance limitado de los dispositivos participativos implantados por estas empresas fabricantes de máquinas-herramienta y su carácer procedimentalizador de las tareas y actividades de los trabajadores han dado lugar al mantenimiento de fenómenos de resistencia del taller frente a las decisiones organizativas de la dirección, basadas en un origen no participativo. Estas actuaciones de resistencia practicadas y desarrolladas colectivamente han supuesto el cuestionamiento, rechazo y subversión de múltiples reglas formales establecidas por la ingeniería de procesos, de manera que los trabajadores intentan ampliar sus espacios de participación autónoma y discrecional mediante la elaboración de sus propias reglas informales que les permiten: a) recuperar ciertas áreas de control sobre su actividad y ritmos de trabajo; b) mantener su soberanía productiva (Kern y Schumann 1988) frente a los resultados expropiadores de los nuevos dispositivos de organización del trabajo; c) redefinir sus obligaciones y adaptar los esquemas de ejecución formales al contexto real de trabajo; d) aumentar sus competencias y obtener contrapartidas que refuerzan su autonomía (Terssac 1991: 98-99); e) así como seguir manteniendo una identidad colectiva de 
gestores expertos de la producción cuyos conocimientos les permiten obtener la producción de manera más eficiente que la propuesta e impuesta por la dirección. La optimización de los resultados empresariales que las reglas informales construidas empírica y colectivamente por los trabajadores permite obtener, supone así una reivindicación del incremento de su participación efectiva en la gestión y definición del proceso de trabajo, haciendo evidente el mantenimiento del conflicto sobre el poder organizativo entre capital y trabajo, entre quienes conciben el proceso y quienes lo ejecutan (entre decisores y ejecutantes) (Terssac 1991: 84), luchando estos últimos por ampliar la frontera de control sobre su propio trabajo, de manera que puedan modelar activamente su propia actividad al margen de las prescripciones gerenciales (Wilkinson 1983: 15-17).

Así mismo, este conflicto se articula de una manera funcional para la propia gerencia, ya que los trabajadores se movilizan en contra de la dirección mediante un juego bélico que enfrenta sus decisiones organizativas mediante el perfeccionamiento voluntario y clandestino para demostrar que sus conocimientos, pericias y regulaciones son, no sólo pertinentes para mejorar la producción, sino mejores que las propuestas por aquellos que se supone poseen el conocimiento experto imprescindible, la ingeniería. El conflicto de los trabajadores se orienta a que se reconozca gerencialmente la importancia de su actividad y de su inteligencia de producción, la necesidad de incrementar su participación en la definición de los procesos de trabajo, lo que intentan mediante una movilización que paradójicamente favorece los objetivos gerenciales (la mejora cuantitativa y cualitativa de la producción), de ahí el carácter funcional de la pervivencia de este conflicto entre taller y dirección. Esta movilización conflictiva pero funcional es la base sobre la que se construye el consentimiento en la producción de los trabajadores: reivindicando la pertinencia de sus conocimientos y de su papel cualificado en la gestión del proceso productivo; creando clandestina e ilegalmente mejores formas de producir que las propuestas por la ingeniería, los propios operadores contribuyen a su explotación en beneficio del capital, obteniendo como única recompensa su propia autoidentificación como agentes productivos imprescindibles y superiores a los organizadores de la producción. Su victoria en el juego bélico contra la dirección y la ingeniería, al demostrarse a sí mismos que sus conocimientos son más útiles que los de aquellos que les ordenan, es la dimensión que permite mantener fluidamente la producción desde el conflicto y así obtener gerencialmente mayor rendimiento efectivo del trabajo humano (Burawoy 1985); una intensificación de la autoexplotación de los trabajadores basada en la reivindicación de su adignidad" como 
productores ${ }^{21}$, así como en el desafío a las decisiones de los organizadores de la producción consideradas equivocadas (Linhart 1997: 95-100). En este contexto, la autonomía de los trabajadores, su iniciativa clandestina y su regulación informal e ilegal, aparecen tanto como condiciones de la eficacia del proceso productivo (Terssac 1995: 81-112), como elementos de construcción de la identidad del trabajo humano y de superación de su tradicional alienación taylorista mediante la conquista de espacios de libertad colectivos (Fantasia, Clawson y Graham 1988: 473): como recurso para imponerse como "productores", para asegurarse un contrapoder y poder desafiar el nuevo orden productivo reconstruido por la innovación gerencial de sus nuevos dispositivos disciplinarios basados en la (limitada y controlada) gestión participativa de los recursos humanos (Linhart 1997: 109-113).

\section{CONCLUSIÓN}

Mediante las experiencias proporcionadas por las políticas de reestructuración y reorganización del sector de empresas fabricantes de máquinas-herramienta es posible trazar o rastrear los contenidos efectivos de la implantación de nuevos conceptos productivos, diseñados gerencialmente, en las realidades de los talleres donde se realizan los procesos de trabajo. Estas nuevas formas de organizar el trabajo pretenden explotar o poner a disposición de las gerencias el conocimiento, la experiencia y la creatividad de la fuerza de trabajo que los disposistivos tayloristas rechazaban e impedían aprovechar. La necesidad de movilizar en favor de la empresa toda esta inteligencia productiva, que los recursos humanos anteriormente mantenían en la clandestinidad, requiere incrementar los espacios de discrecionalidad de los trabajadores para que puedan utilizar sus yacimientos de conocimiento de forma autónoma en su puesto, lo cual se consigue en esta nueva perspectiva posibilitando la participación de los trabajadores en la gestión del proceso de trabajo. La participación

21 La construcción de reglas informales por parte del obrero colectivo implica que la racionalización taylorista que separa la concepción de la ejecución elabora prescripciones cuyo respeto no permite lograr la producción (Terssac 1991: 100); de hecho, la explotación de las iniciativas y conocimientos de los ejecutantes (de sus yacimientos de pericias informales) es la base de la nueva racionalización defendida (teóricamente) por los nuevos conceptos productivos antropocéntricos o toyotistas, aunque sea en sus prácticas efectivas donde se deba comprobar, como se ha hecho a lo largo de esta investigación, hasta qué punto se permite la participación necesaria para este tipo de racionalización supuestamente no taylorista. 
se constituye simultáneamente como un dispositivo directivo que busca involucrar a los operadores en sus objetivos productivos; es decir, reducir o eliminar el tradicional enfrentamiento entre capital y trabajo de manera que ambos cooperen armoniosamente en la consecución de esos objetivos. Para ello, la participación supone la actuación gerencial sobre los trabajadores para que estos adquieran nuevas actitudes colaboradoras, pretendiendo acuñar o modelar en la fuerza de trabajo nuevos comportamientos que garanticen que ésta pone a disposición de la empresa esa inteligencia de producción tan valorada ahora, pretendiendo reconstruir un orden en la producción que, mediante el reconocimiento gerencial de la propia participación, facilite el mantenimiento y reproducción del consentimiento de los trabajadores a someterse a la disciplina de trabajo y a su explotación sin conflictos perturbadores del proceso de fabricación.

Sin embargo, el diseño de estos nuevos conceptos participativos depende en su implantación de los propios procesos colectivos de regulación de los trabajadores afectados, que pueden aceptar pero también rechazar las nuevas prácticas gerenciales, como ocurre en las empresas fabricantes de máquinas-herramienta analizadas, en las que los trabajadores niegan el carácter participativo de estos conceptos, enfrentándose a las reglas formales de trabajo impuestas por la dirección mediante la construcción colectiva de reglas informales que les permiten subvertir las decisiones directivas y obtener la producción en mejores condiciones que si hubieran seguido los mandatos de las ingenierías. Su enfrentamiento se basa en la necesidad de la fuerza de trabajo de autoidentificarse como recurso de fiabilidad del proceso de fabricación, frente a una ingeniería que sigue cuestionando ese papel, reproduciéndose su consentimiento en la producción no por los efectos de la delegación de participación desde la gerencia, sino por el propio mantenimiento del conflicto entre capital y trabajo, de esta fractura entre oficina y taller, que, sin embargo, es funcional, en este caso, para la propia gerencia a la que se enfrentan los operadores al incrementar estos su autoexplotación. En definitiva, la emergencia de un nuevo modelo productivo es mucho más que una transformación de la organización del trabajo, puesto que es fundamentalmente la práctica de una apuesta de modelación de la fuerza de trabajo, de su disciplina mediante los dispositivos que suponen los nuevos conceptos productivos. De esta forma, la empresa aparece como un laboratorio cultural de fabricación de sujetos, cuyos resultados dependerán de la propia interacción y movilización de los actores involucrados —capital y trabajo-; de sus estrategias de cooperación y enfrentamiento.

Por último, a pesar de que ha sido tratado en otro lugar (Lahera Sánchez 1998), rastrear el origen de la construcción colectiva de la identidad de los 
trabajadores permite conocer en profundidad las formas de regulación obrera del propio proceso de producción y su influencia en los resultados empresariales; conocimiento que tan sólo puede ser obtenido mediante un exhaustivo y prolongado trabajo de campo en los espacios y terrenos contextuales donde tienen lugar estos fenómenos: en los talleres y oficinas de las empresas, en las que los enfoques, metodologías y recursos de la antropología son actual y totalmente pertinentes.

\section{BIBLIOGRAFÍA CITADA}

AENOR. 1994. Normas para la gestión y el aseguramiento de la calidad ISO-9000.

ARAGón, A. 1998. La participación de los empleados en la empresa. Madrid: Consejo Económico y Social.

BADíA, A. y S. Bellido. 1999. Técnicas para la gestión de la calidad. Madrid: Tecnos. BOYER, R. y M. FREYSSENET. 1996. "Emergencia de nuevos modelos industriales". Sociología del Trabajo 27: 23-54.

Burawoy, M. 1985. El consentimiento en la producción. Madrid: Ministerio de Trabajo. BUTERA, F. 1986. El cambio organizativo en la gran empresa en Italia. Madrid: Ministerio de Trabajo.

CASTILLO, J. J. 1991. Las nuevas formas de organización del trabajo. Madrid: Ministerio de Trabajo. 2." ed.

- 1996. "Un fantasma recorre Europa... de nuevo, la producción ligera". Sociología del Trabajo 27: 3-21.

- 1998. A la buisqueda del trabajo perdido. Madrid: Tecnos.

CONTI, R. F. y M. WARNER. 1993. "Taylorism, new technology and just-in-time systems in Japanese manufacturing.. New Technology, Work and Employment 8 (1): 31-42.

CRESSEY, P. y V. Di MARTINO. 1991. Agreement innovation. The international dimension of technical change. London: Prentice Hall.

DANKBAAR, B. 1989. "Technical change and industrial relations: Theoretical reflections on changes in the automobile industry. Economic and Industrial Democracy 10 (1): 99-121.

Delbridge, R., P. Turnbull y B. Wilkinson. 1992. "Pushing back the frontiers: management control and work intensification under JIT/TQM factory regimes". New Tecbnology, Work and Employment 7 (2): 97-106.

Fantasia, R., D. Clawson y G. Graham. 1988. "A critical view of worker participation in American industry. Work and Occupations 15 (4): 468-488.

FRIEDMANN, G. 1978. La crisis del progreso. Barcelona: Laia.

Gaudemar, J. P. De. 1991. El orden en la producción. Madrid: Trotta.

GRZYB, G. J. 1981. "Decollectivization and recollectivization in the workplace: the impact of technology on informal groups and work culture. Economic and Industrial Democracy 2 (4): 455-482.

KeRn, H. y M. SChumanN. 1988. El fin de la división del trabajo. Madrid: Ministerio de Trabajo.

LAHERA SÁNCheZ, A. 1998. «Fábrica y comunidad: Transformación del trabajo e interdisciplinariedad en las Ciencias Sociales del Trabajon. Sociología del Trabajo 33: 71-102. 
- 2000. La emergencia de nuevos modelos productivos y la participación de los trabajadores. Diseño e implantación de conceptos antropocéntricos de producción en empresas fabricantes de máquinas-berramienta. Tesis Doctoral, Departamento de Sociología III, Facultad de CC. Políticas y Sociología. UCM.

LINHART, D. 1990. "¿Qué cambios en la empresa?. Sociología del Trabajo 11: 25-48.

- 1997. La modernización de las empresas. Buenos Aires: Asoc. Trabajo y Sociedad.

MARTín CRIADO, E. y J. IZQUiERdo MARTín. 1993. "Elementos para una sociología económica de la gestión empresarial de la fuerza de trabajon. Sociología del Trabajo 17: $121-145$

Miller, P. y T. O'LEARY. 1994. "The factory as a laboratory". Science in Context 7 (3): 469-496.

Mills, C. W. 1948. "The contribution of sociology to studies of industrial relations" Industrial Relations Research Association: 199-222.

OMPES-Fuenlabrada. 1998. Guía práctica para la implantación de un Sistema de Calidad ISO 9000. Ayuntamiento de Fuenlabrada.

SANDBERG, A. 1995. Enriching Production. London: Avebury.

SARRIÉs, L. 1994. Nuevos modelos de onganización industrial: un análisis sociológico. Madrid: Dykinson.

SCHUMANN, M. 1998. "New concepts of production and productivity". Economic and Industrial Democracy 19 (1): pp. 17-31 (Monográfico: Good work and productivity).

- 1999. "El desarrollo del trabajo industrial: nuevas contradicciones", en J.J. Castillo (ed.), El trabajo del futuro: 83-97. Madrid: Ed. Complutense.

SENLLE, A. y G. STOLL. 1995. Calidad total y normalización: ISO 9000. Barcelona: Gestión 2000.

SMITH, C. 1989. "Especialización flexible, automatización y producción en serie». Sociología del Trabajo 7: 35-61.

TAUSKY, C. y A. F. CHELTE. 1988. "Workers' participation". Works and Occupation 15 (4): $363-373$.

TAYLOR, F. W. 1925. La dirección de los talleres. Barcelona: Feliu y Susanna.

- 1971. Principios de la administración científica. Barcelona: Oikos.

TERSSAC, G. 1991. "Trabajo colectivo y división del trabajo". Sociología del Trabajo 11: 83-103.

- 1995. Autonomía en el trabajo. Madrid: Ministerio de Trabajo.

Troussier, J. F. 1987. "Considerations on the collective dimension of work". New Technology, Work and Employment 2 (1): 37-46.

UNITED STATES COMMISSION ON INDUSTRIAL RELATIONS. 1914. Efficiency systems and labor, Declaración de F. W. Taylor. Washington, D. C.

VV. AA. 1997. La emergencia de nuevos modelos productivos (monográfico). Sociología del Trabajo 27.

WEIR, S. 1973. "The informal workgroup", en A. Lynd (ed.), Rank and File: 172-200. Boston: Beacon Press.

WILKINSON, G. 1983. The shopfloor politics of new technology. Hampshire: Gower.

WoBBE, W. 1991. Anthropocentric Production Systems: A Strategic Issue for Europe. Bruselas: Fast-Monitor-Comisión Europea.

WOMACK, J. P., D. T. JONES y D. ROOS. 1991. The machine that change the world. New York: Harper Collins.

WoOD, S. (ed.). 1989. The transformation of work? London: Unwing Hyman. 